\title{
Data assimilation of photosynthetic light-use efficiency using multi-angular satellite data: II Model implementation and validation
}

\author{
Thomas Hilker ${ }^{\text {a,* }}$, Forrest G. Hall a ${ }^{\text {, Compton J. Tucker }}{ }^{\mathrm{a}}$, Nicholas C. Coops ${ }^{\mathrm{b}}$, T. Andrew Black ${ }^{\mathrm{c}}$, \\ Caroline J. Nichol d, Piers J. Sellers ${ }^{\text {a }}$, Alan Barr ${ }^{\mathrm{e}}$, David Y. Hollinger ${ }^{\mathrm{f}}$, J.W. Munger ${ }^{\mathrm{g}}$ \\ a NASA Goddard Space Flight Center, Biospheric Sciences Branch, Code 618, Greenbelt, MD 20771 USA \\ ${ }^{\mathrm{b}}$ Faculty of Forest Resources Management, University of British Columbia, 2424 Main Mall, Vancouver, BC, Canada V6T 1 Z4 \\ c Faculty of Land and Food Systems, University of British Columbia, 2357 Main Mall, Vancouver, BC, Canada V6T $1 Z 4$ \\ d School of Geosciences, University of Edinburgh, West Mains Road, Edinburgh EH9 3JN, Scotland UK \\ e Environment Canada, 11 Innovation Blvd., Saskatoon, SK, Canada \\ ${ }^{\mathrm{f}}$ US Forest Service, Northern Research Station, 271 Mast Rd, Durham, New Hampshire, USA \\ ${ }^{g}$ Harvard University, Cambridge, MA, USA
}

\section{A R T I C L E I N F O}

\section{Article history:}

Received 26 August 2011

Received in revised form 4 February 2012

Accepted 5 February 2012

Available online xxxx

\section{Keywords:}

Data assimilation

Photosynthesis

Eddy-flux

Multivariate function

Epsilon

Epsilon max

Global carbon cycle

Carbon modeling

Vegetation carbon cycle

Downregulation

CHRIS/Proba

PRI $^{\prime}$

Multi-angular

\begin{abstract}
A B S T R A C T
Spatially explicit and temporally continuous estimates of photosynthesis will be of great importance for increasing our understanding of and ultimately closing the terrestrial carbon cycle. Current capabilities to model photosynthesis, however, are limited by accurate enough representations of the complexity of the underlying biochemical processes and the numerous environmental constraints imposed upon plant primary production. A potentially powerful alternative to model photosynthesis through these indirect observations is the use of multi-angular satellite data to infer light-use efficiency $(\varepsilon)$ directly from spectral reflectance properties in connection with canopy shadow fractions. Hall et al. (this issue) introduced a new approach for predicting gross ecosystem production that would allow the use of such observations in a data assimilation mode to obtain spatially explicit variations in $\varepsilon$ from infrequent polar-orbiting satellite observations, while meteorological data are used to account for the more dynamic responses of $\varepsilon$ to variations in environmental conditions caused by changes in weather and illumination. In this second part of the study we implement and validate the approach of Hall et al. (this issue) across an ecologically diverse array of eight flux-tower sites in North America using data acquired from the Compact High Resolution Imaging Spectroradiometer (CHRIS) and eddy-flux observations. Our results show significantly enhanced estimates of $\varepsilon$ and therefore cumulative gross ecosystem production (GEP) over the course of one year at all examined sites. We also demonstrate that $\varepsilon$ is greatly heterogeneous even across small study areas. Data assimilation and direct inference of GEP from space using a new, proposed sensor could therefore be a significant step towards closing the terrestrial carbon cycle.
\end{abstract}

(c) 2012 Elsevier Inc. All rights reserved.

\section{Introduction}

Global models of plant photosynthesis are limited in their ability to infer the spatial and temporal heterogeneity of photosynthetic light-use efficiency $(\varepsilon)$, the efficiency with which plants can use absorbed radiation energy to produce biomass. This $\varepsilon$ is driven by numerous environmental constraints affecting the photochemical reaction chain, and varies greatly in space and time. Our limited understanding of the underlying biochemical processes (Field \& Mooney, 1986) and difficulties in obtaining the driving variables globally are major limitations to current approaches modeling photosynthesis (Turner et al., 2003).

\footnotetext{
* Corresponding author. Tel.: +1 301286 8597; fax: +1 3016146695 E-mail address: thomas.hilker@nasa.gov (T. Hilker).
}

A potentially powerful alternative to deriving $\varepsilon$ from environmental constraints is to directly infer the status of the xanthophyll cycle, a biochemical mechanism that balances light use and absorption in higher plants (Demmig-Adams \& Adams, 1996). Under conditions where light use efficiency is limited by factors other than light, the xanthophyll cycle pigment violaxanthin is rapidly converted via intermediate antheraxanthin to zeaxanthin, both of which have biochemical structures that allow the dissipation of excessive radiation energy as heat. This pigment conversion can be quantified by the photochemical reflectance index (PRI), a narrow waveband index that uses a xanthophyll specific absorption band at $531 \mathrm{~nm}$, however, confounding background and bi-directional reflectance effects have hampered its use for almost two decades (Coops et al., 2010). Recent progress using multi-angular observations(Hall et al., 2008), has allowed us, for the first time to infer $\varepsilon$ across a large range of forested ecosystems from space using one functional relationship, the first 
derivative of PRI with respect to shadow fractions $\left(\alpha_{\mathrm{s}}\right)$, hereafter referred to as PRI'. Theoretical (Hall et al., 2011, 2008) and empirical work (Hilker et al., 2011, 2010a) has given this multi-angular method a solid foundation as generic, physically based measure of light-use efficiency: PRI' is insensitive to background reflectance and reflectance of non-photosynthetically active material, because for single leaf scattering, a valid assumption for wavelengths in the visible bands, Hall et al. (2008) showed that PRI cannot change its value with shadow fraction unless the value of one of its bands changes as a physiological response to the degree of leaf illumination. Hilker et al. (2011) implemented these theoretical considerations over a range of different study sites using multi-angle satellite data. The results are summarized in Fig. 1 and illustrate the capacity of this method to infer $\varepsilon$ across a large range of at least temperate and boreal ecosystems from space. As a result, this new technique could bypass much of the difficulties experienced in modeling $\varepsilon$ from environmental constraints.

In the first part of this study (Hall et al., this issue) we described a simple approach for modeling $\varepsilon$ from data assimilation of $\mathrm{PRI}^{\prime}$ and meteorological constraints. In the forward mode, our model down regulates a spatially explicit maximum convergence efficiency $\left(\varepsilon_{\text {opt }}\right)$ using a non-linear, multivariate response function of photosynthetically active radiation (PAR), temperature ( $T$ ) and water vapor pressure deficit (D) to obtain temporally continuous estimates of GEP at a $30 \mathrm{~m}$ spatial resolution. This multivariate function accounts for the variability in $\varepsilon$ due to the highly dynamic changes in the environment in between satellite overpasses. However, since $\varepsilon$ can also be observed directly during a satellite overpass, these spaceborne observations can be used together with corresponding measures of PAR, T and $\mathrm{D}$ during the spacecrafts overpass time to invert the model and infer a pixel specific $\varepsilon_{\text {opt }}$. This $\varepsilon_{\text {opt }}$ can be re-determined every few satellite overpasses, and as a result, can be used to describe more inert changes in the conditions affecting $\varepsilon$ (such as soil nutrient status and edaphic water stresses for instance), thereby reducing much of the complexity of modeling GEP(Hall et al., this issue).

In this second paper we evaluate our new approach across a number of temperate forest sites using observations from the Compact High Resolution Imaging Spectroradiometer (CHRIS), a demonstration sensor of the European Space Agency (ESA) aboard the Platform for On Board Autonomy (Proba). First, meteorological response

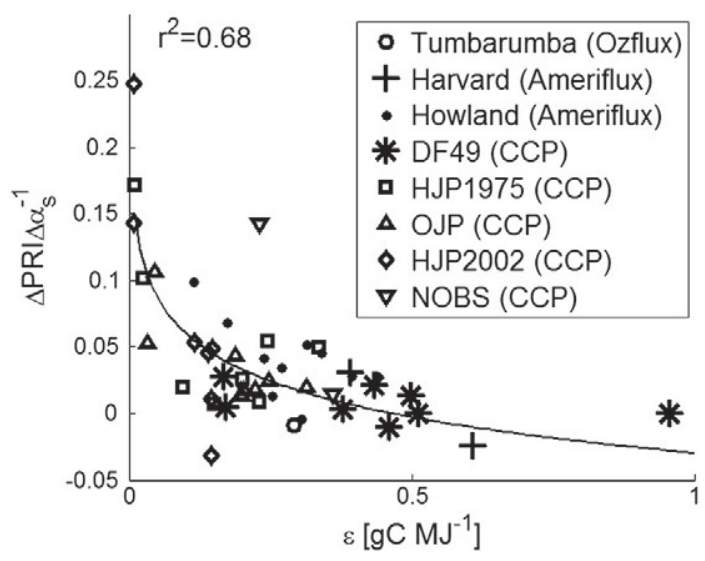

Fig. 1. Relationship between PRI' as observed from CHRIS/Proba imagery and EC measured $\varepsilon$ for DF-49, Harvard Forest, HJP1975, HJP2002, Howland Forest, Northern Old Black Spruce, Old Jack Pine and Southern Old Aspen. All observations have been collected between 2001 and 2009. The study demonstrated that even over a large different canopies, a consistent relationship was can be established between $\mathrm{PRI}^{\prime}$ and $\varepsilon$, hence PRI' serves as a generic tool to measure $\varepsilon$ remotely.

From Hilker et al. (2011) Journal of Geophysical Research, Vol. 116, G03014, Reproduced by permission of American Geophysical Union. functions are evaluated using eddy flux observations made at eight different tower sites throughout North America. Our T and D functions are compared to response functions of the MODIS GEP algorithm (MOD17) (Heinsch et al., 2006; Running et al., 2004; Zhao et al., 2005), a commonly used technique to assessing global carbon uptake from earth observing satellites. Also, we use CHRIS/Proba data to investigate the spatial heterogeneity of $\varepsilon_{\text {opt }}$ across and within the different study sites used in this paper.

\section{Methods}

\subsection{Study sites}

Eight different sites were selected to evaluate our model. The selected sites span a broad range of temperate forest types despite a limited range due to the availability of simultaneous eddy-flux tower observations and CHRIS/Proba satellite data. Table 1 provides a description of the study locations and data availability. The structure of the different sites ranged from recently harvested, regenerating Jack pine (Pinus banksiana Lamb.) dominated forest (HJP2002) to mature, Douglas-Fir (Pseudotsuga menziesii var menziesii (Mirb.)) dominated (e.g. DF-49) and Aspen (Populus tremuloides Michx) dominated (e.g. SOA) stands (see Fig. 2 for in situ photographs of all sites). For all but one site (SOA), CHRIS/Proba data were available in conjunction with eddy flux observations and have been collected between 2001 and 2009.

\subsection{Eddy flux and meteorological data}

Canopy GEP was determined from eddy-covariance (EC) measurements acquired from the data archive of the Canadian Carbon Program (CCP) for the Canadian sites and Ameriflux for the two US sites (Table 1). Net ecosystem exchange (NEE) was determined as the sum of the half-hourly fluxes of $\mathrm{CO}_{2}$ and the rate of change in $\mathrm{CO}_{2}$ storage in the air column between ground and ECmeasurement level (Barr et al., 2004), fluxes for the Harvard site were available as hourly observations (Horii et al., 2004).

Incident and reflected PAR [ $\left.\mu \mathrm{mol} \mathrm{m}{ }^{-2} \mathrm{~s}^{-1}\right]$ was measured from upward and downward looking quantum sensors above and below the canopy and the fraction of PAR absorbed by the canopy $\left(f_{P A R}\right)$ was derived at each site from the incident and reflected total PAR measured above and below the canopy $\left(\rho_{1}(\theta)\right.$ and $\left.\rho_{2}(\theta)\right)$, the effective leaf area index $\left(L_{e}\right)$, and the solar zenith angle $(\theta)$ at the time of measurement (Chen, 1996). GEP was determined as the difference between NEE and daytime ecosystem respiration $\left(R_{D}\right)$ (Humphreys et al., 2006) as provided by the respective flux network. $R_{D}$ was calculated using the annual exponential relationship between nighttime NEE and soil temperature at 5-cm depth after applying a logarithmic transformation to correct for heteroscedasticity (Black et al., 1996). Light-use efficiency was derived from (Monteith, 1972, 1977)

$\varepsilon=\frac{G P P}{P A R \times f_{P A R}}$

More detailed descriptions on processing of the eddy-covariance data can be found in (Humphreys et al., 2006), a comprehensive review on Fluxnet procedures and processing of EC-data is provided in (Baldocchi, 2003).

Above-canopy air temperature $(\mathrm{T})$ and relative humidity were derived from temperature and humidity probes housed in aspirated shields (Humphreys et al., 2006). Atmospheric water vapor pressure deficit $(D)$ was computed from T and relative humidity (Buck, 1981) and PAR was derived directly from the incoming PAR sensors. 
Table 1

Site description and available CHRIS/Proba scenes. The overpass time varies by up to several minutes per site. All times are given in GMT.

Site description is adapted from Hilker et al., 2011.

\begin{tabular}{|c|c|c|c|c|c|c|c|c|}
\hline Site, Reference & $\begin{array}{l}\text { Lat }\left({ }^{\circ}\right) / \\
\text { Long }\left({ }^{\circ}\right)\end{array}$ & $\begin{array}{l}\text { Elev } \\
(\mathrm{m})\end{array}$ & Dominant species & $\begin{array}{l}\text { Leaf area } \\
\text { index }\end{array}$ & $\begin{array}{l}\text { Age } \\
\text { (years) }\end{array}$ & $\begin{array}{l}\text { Height } \\
(\mathrm{m})\end{array}$ & $\begin{array}{l}\text { Annual } \\
\text { mean temp. } \\
\left({ }^{\circ} \mathrm{C}\right)\end{array}$ & $\begin{array}{l}\text { \# of avail. } \\
\text { CHRIS- scenes/approx. } \\
\text { overpass time }\end{array}$ \\
\hline DF-49 (Morgenstern et al., 2004) & $\begin{array}{l}-125.334 \\
49.867\end{array}$ & 340 & $\begin{array}{l}\text { Pseudotsuga menziesii, Thuja } \\
\text { plicata, Tsuga heterophylla }\end{array}$ & 7.1 & 60 & 35 & 8.1 & $\begin{array}{l}6 \\
18: 45\end{array}$ \\
\hline $\begin{array}{l}\text { Harvard (Munger et al., 1996; Staebler \& } \\
\text { Fitzjarrald, 2005) }\end{array}$ & $\begin{array}{l}-72.171 \\
42.537\end{array}$ & 340 & $\begin{array}{l}\text { Quercus rubra, Acer rubrum, Betula } \\
\text { lenta, Pinus strobus,Tsuga canad }\end{array}$ & 3.4 & 80 & 23 & 8.3 & $\begin{array}{l}2 \\
16: 01\end{array}$ \\
\hline $\begin{array}{l}\text { HJP1975 (Amiro et al., 2006; Chen et al., } \\
\text { 2006; Schwalm et al., 2006; Zha et al., 2009) }\end{array}$ & $\begin{array}{l}-104.645 \\
53.876\end{array}$ & 570 & Pinus banksiana & 1.4 & 35 & 6 & 0.4 & $\begin{array}{l}9 \\
18: 09\end{array}$ \\
\hline $\begin{array}{l}\text { HJP2002 (Amiro et al., 2006; Chen et al., 2006; } \\
\text { Kidston et al., 2010; Schwalm et al., 2006) }\end{array}$ & $\begin{array}{l}-104.649 \\
53.908\end{array}$ & 560 & Pinus banksiana & 0.9 & 8 & 0.1 & 0.4 & $\begin{array}{l}9 \\
18: 09\end{array}$ \\
\hline $\begin{array}{l}\text { Howland (Hollinger et al., 2004; } \\
\text { Xiao et al., 2005) }\end{array}$ & $\begin{array}{l}-68.740 \\
45.204\end{array}$ & 60 & Picea rubens, Tsuga canadensis & 5.3 & 109 & 20 & 6.7 & $\begin{array}{l}3 \\
15: 18\end{array}$ \\
\hline NOBS (Bergeron et al., 2007) & $\begin{array}{l}-98.481 \\
55.880\end{array}$ & 259 & Picea mariana & 4.8 & 160 & 9 & -4.4 & $\begin{array}{l}6 \\
18: 14\end{array}$ \\
\hline $\begin{array}{l}\text { OJP (Amiro et al., 2006; Chen et al., 2006; } \\
\text { Schwalm et al., 2006) }\end{array}$ & $\begin{array}{l}-104.692 \\
53.916\end{array}$ & 579 & Pinus banksiana & 2 & 91 & 13 & 0.4 & $\begin{array}{l}9 \\
18: 09\end{array}$ \\
\hline SOA (Barr et al., 2004) & $\begin{array}{l}106.198 \\
-52.629\end{array}$ & 600 & $\begin{array}{l}\text { Populus tremuloides } \\
\text { Corylus cornuta }\end{array}$ & 2.1 & 83 & 22 & 0.4 & 0 \\
\hline
\end{tabular}

\subsection{Shadow fractions}

Estimation of canopy shading $\left(\alpha_{\mathrm{s}}\right)$ is critical for accurate modeling of canopy light-use efficiency, as sunlit parts of the canopy are more likely to be exposed to excessive radiation energy than shaded vegetation elements (Hilker et al., 2008b). For instance, Hall et al. (2008) showed that canopy level measurements of the photochemical reflectance index (PRI) are strongly dependent on $\alpha_{s}$, and that the directional changes observed in PRI at a given half hour interval can be attributed almost entirely to changes in $\alpha_{\mathrm{s}}$ (Hall et al., 2008).
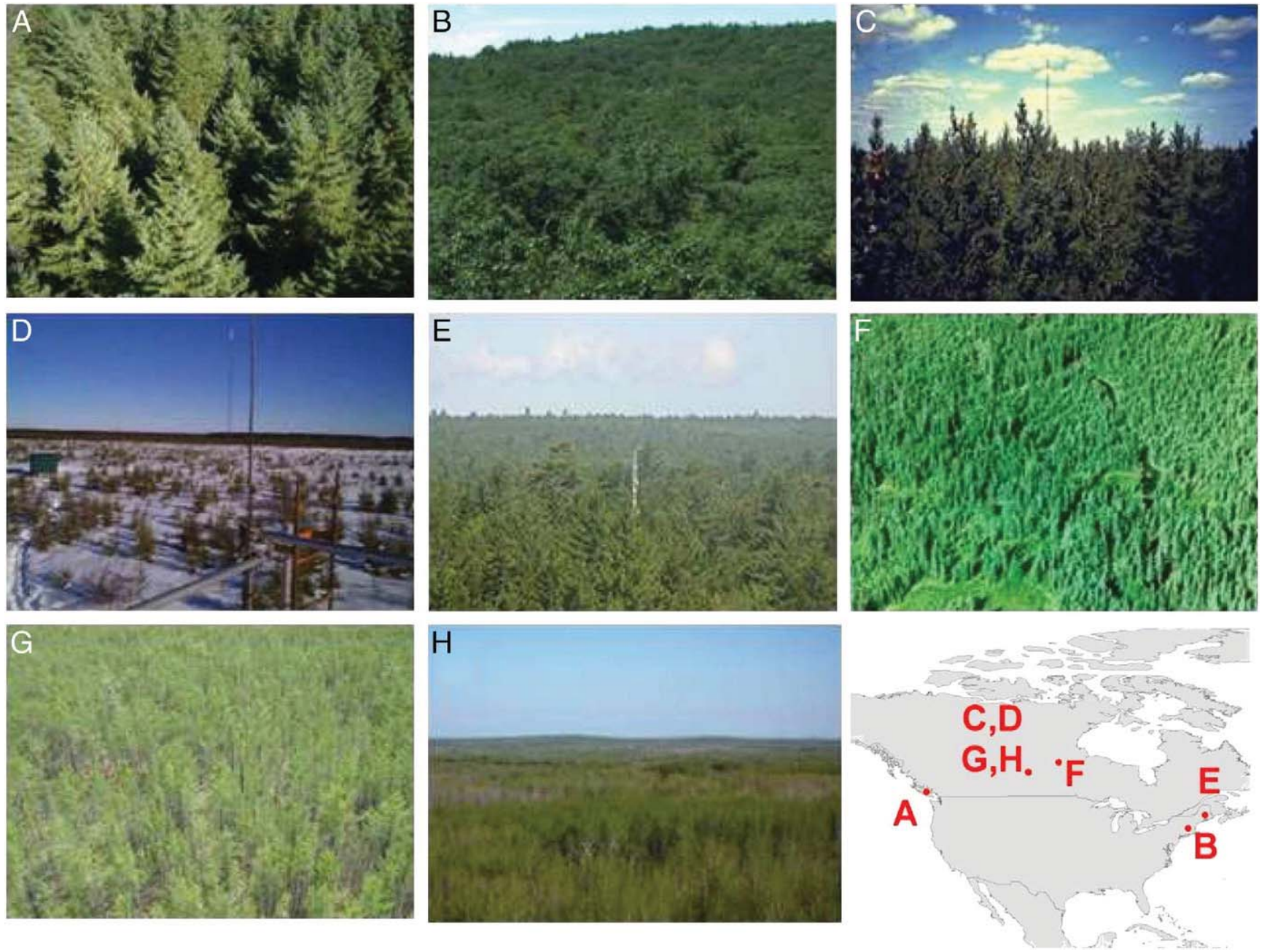

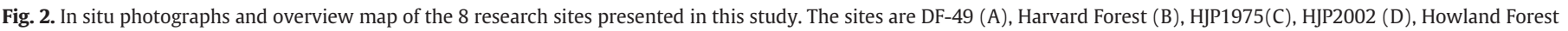
$(E)$, Northern Old Black Spruce (F), Old Jack Pine $(G)$ and Southern Old Aspen (H). 
In previous studies (Hall et al., 2008; Hilker et al., 2008a, 2010a) we have used airborne light detection and ranging (LiDAR) to estimate canopy shading. While this approach yields a good approximation of mutual shading of individual stands, LiDAR data were not available for all of the sites. As a result, we determined $\alpha_{s}$ at all flux-tower sites using a geometric optical model (Li \& Strahler, 1985), which estimates mutual canopy shading using measures of tree and crown dimensions and estimates tree density. Those measurements were available from previous field measurements (Hilker et al., 2010b) and published values (Amiro et al., 2006; Bergeron et al., 2007; Chen et al., 2006; Schwalm et al., 2006; Staebler \& Fitzjarrald, 2005; Xiao et al., 2005) for the different flux tower sites.

Canopy shading effectively increases the proportion of diffuse sky radiation by blocking direct sunlight from parts of the canopy. The magnitude of this effect depends on the fraction of diffuse sky radiation and is largest under direct illumination conditions, while nonexistent under completely cloudy skies. While not all of the sites used in these studies provided direct measurements of the diffuse sky radiation, the proportion of diffuse radiation can be approximated when comparing the measured incident PAR to modeled clear sky conditions as a function of the solar zenith angle (Hilker et al., 2009a). Clear sky solar irradiance was modeled from maximum PAR observations obtained for a range of zenith angles at each site and sky conditions were estimated as the fraction of actually measured irradiance to the maximum solar potential for that zenith angle at a given point in time. For details see (Hilker et al., 2009a).

\subsection{CHRIS/Proba imagery}

CHRIS is an imaging spectrometer with a $615 \mathrm{~km}$ sunsynchronous orbit and an orbital repeat cycle of approximately 7 days. The CHRIS/Proba configuration permits along-track narrowband spectrometric observations of PRI of up to five angles $\left(+55^{\circ}\right.$, $+36^{\circ}, 0^{\circ},-36^{\circ},-55^{\circ}$ ) at a maximum spatial resolution between $18 \mathrm{~m}$ or $34 \mathrm{~m}$ depending on the data acquisition mode. This data is acquired nearly simultaneously within each overpass during which stand level $\varepsilon$ may be considered constant. CHRIS/Proba images acquired between 2001 and 2009 were obtained for 8 of the test sites (no data were available for the SOA site) from ESA's online archive (https://oa-es.eo.esa.int/ra/). The image size of CHRIS/Proba scenes is approximately $25 \times 25 \mathrm{~km}$ at nadir.

CHRIS data collected in modes 1 and 3 were used, as they provided the appropriate PRI wavebands at around 531 and $570 \mathrm{~nm}$. The satellite observations were pre-processed using the VISAT tool of the European Space Agency (Gomez-Chova et al., 2008), to convert satellite measured radiance to top of atmosphere reflectance and screen the images for clouds (Thuillier et al., 2003). A two step georectification algorithm was applied (Ma et al., 2010) and CHRIS/ Proba satellite images were registered with respect to Landsat observations of the same locations (Hilker et al., 2011). First, common ground control points (GCPs) between Landsat and CHRIS/Proba were automatically identified using a scale-invariant feature transform (SIFT) (Lowe, 2004). The network of these initial GCPs was then enhanced in a second step using a normalized cross correlation (NCC) approach.

Satellite observed reflectance depends on two main parameters, aerosol optical thickness (AOT) and surface reflectance (SR). To correct for the impact of atmospheric effects, commonly used, pixel based algorithms of atmospheric correction assume a Lambertian surface reflectance. Hilker et al. (2009a, 2009b) showed that this assumption directly contradicts the multi-angle effects observed in PRI and consequently, no meaningful multi-angular observations of PRI can be obtained from single orbit atmospheric corrections (Hilker et al., 2009b). This challenge could potentially be overcome when using a time series approach for which the retrieval of aerosol optical thickness does not require these simplifying assumptions
(Hilker et al., 2009b; Lyapustin et al., 2007); however, no such algorithm currently exists for CHRIS/Proba. Using radiative transfer theory, it can be shown that atmospheric path scattering will cause PRI to increase with $\alpha$ s hence depress PRI' and the estimate of [epsilon] (Hall et al., 2011). PRI' will be affected by the effects of different path lengths through the atmosphere, but not the absolute change in PRI due to lack of atmospheric correction. The limitations due the lack of atmospheric correction are acknowledged, the calculated error (Hall et al., 2011) should, however, still allow the demonstration of the proposed model from top of atmosphere reflectance.

PRI was computed from CHRIS/Proba imagery as the normalized difference of CHRIS bands 4 (529 nm, Bandwidth: $12.9 \mathrm{~nm}$ ) and 6 ( $569 \mathrm{~nm}$, Bandwidth: $14.1 \mathrm{~nm}$ ) for images acquired in CHRIS Mode 3 (all sites except for the southern BOREAS region), and band 11 (532 nm, Bandwidth $13.4 \mathrm{~nm}$ ) and 15 (573 nm, Bandwidth $9.6 \mathrm{~nm}$ ) for images acquired in CHRIS Mode 1 (Hilker et al., 2011). PRI and corresponding $\alpha_{s}$ were computed for each pixel of a multi-angular image stack acquired during one overpass (Hilker et al., 2011). Please note that the slope of PRI with respect to canopy shading $\left(\alpha_{s}\right)$ is non linear, as demonstrated in Hall et al. (2011). However, this non-linearity is most important near the dark spot. For the purpose of this study, we have used a linear regression of PRI vs. $\alpha_{s}$ to simplify the processing, as the CHRIS/Proba data observes all scenes at roughly the same range of shadow fractions at all times, and these view angles, and Hilker et al. (2011) showed that for this data the slope can be approximated as simple linear regression.

\subsection{Model inversion}

Inversion of our multivariate model (Hall et al., this issue) allows the parameterization of $\varepsilon_{\text {opt }}$ across the landscape from CHRIS/Proba reflectance. In the forward mode, the photosynthesis model introduced in this study provides estimates of light-use efficiency for a given set of landscape parameters, i.e. D, T, PAR and $\varepsilon_{\text {opt }}$. In the inverse mode, the CHRIS/Proba inferred $\varepsilon$ can be used to derive $\varepsilon_{\text {opt }}$ for every given pixel of a satellite scene, assuming that solar irradiance, $\mathrm{D}$ and $\mathrm{T}$ are constant across the scene (which is reasonable to a first approximation given the limited spatial extend of CHRIS/ Proba of approximately $20 \times 20 \mathrm{~km}$ ).

Mathematically, model inversion is a non-linear minimization problem that can be solved through iterative adjustment of estimated a-priori inputs (Verstraete et al., 1996). Different optimization algorithms are available, based on cost functions to minimize the residuals between forward modeled and measured observations (here: canopy reflectance). In this study, we selected a trust-regionreflective algorithm based on the interior-reflective Newton method (Coleman \& Li, 1996; Coleman et al., 2002). The search range of $\varepsilon_{o p t}$ was set to $0-4 \mathrm{~g} \mathrm{C} \mathrm{MJ}^{-1}$ for all sites based on an extensive review by Schwalm et al. (2006).

Technically, model inversion would also allow inference of the shape parameters introduced for the response functions of $D, T$ and PAR. However, the limited availability of CHRIS/Proba data makes a dynamic inference of these parameters difficult. As a result, we determined the parameters of the response functions empirically, by inverting the model using eddy-flux observations and assuming the shape parameters to be constant across all sites.

\section{Results}

The first section of the results presents a comparison between the response function introduced in Hall et al. (this issue) and EC-flux data. In order to evaluate the degree to which our multivariate, non-linear response functions improves the GEP estimates over the MODIS MOD17 approach, we use the MOD17 performance as a baseline. The second section shows the results from model inversion using the CHRIS/Proba data. 
Fig. 3 shows the dependency of $\varepsilon$ on D and T and PAR across the eight different research sites selected for this study. The X-axis represents the temperature response curve for a given level of $D$, the $Y$-axis shows the $\mathrm{D}$ response curve for a given temperature level. The characteristic shapes of both response functions are clearly visible in the model (compare Hall et al., this issue; Figs. 3, 4 and 7). The shape of the three dimensional mesh-surface reflects the multi-variate nature of our model. For instance, when $T$ is near the optimum, $\varepsilon$ tends to be higher for a given level of $D$, because one stress factor has less of an impact than if two stresses affect photosynthesis at the same time. The dots represent actual observations of T, D and corresponding $\varepsilon$ made by the eddy covariance systems and averaged as hourly observations. The colors of the data points correspond to different levels of PAR (red = high, blue $=$ low). As the physiology predicts, high levels of PAR yielded low levels of $\varepsilon$. Again, down-regulation is more rapid, when one or both of the other limiting factors ( $\mathrm{T}$ and $\mathrm{D}$ ) are sub-optimal. For instance, higher PAR levels yielded high $\varepsilon$ values only when temperatures were near optimum (see for instance Figure B); otherwise $\varepsilon$ was low, even if PAR was low. The three dimensional mesh represents the fit of the physiologically based response functions to the data, the colors of the mesh-surface
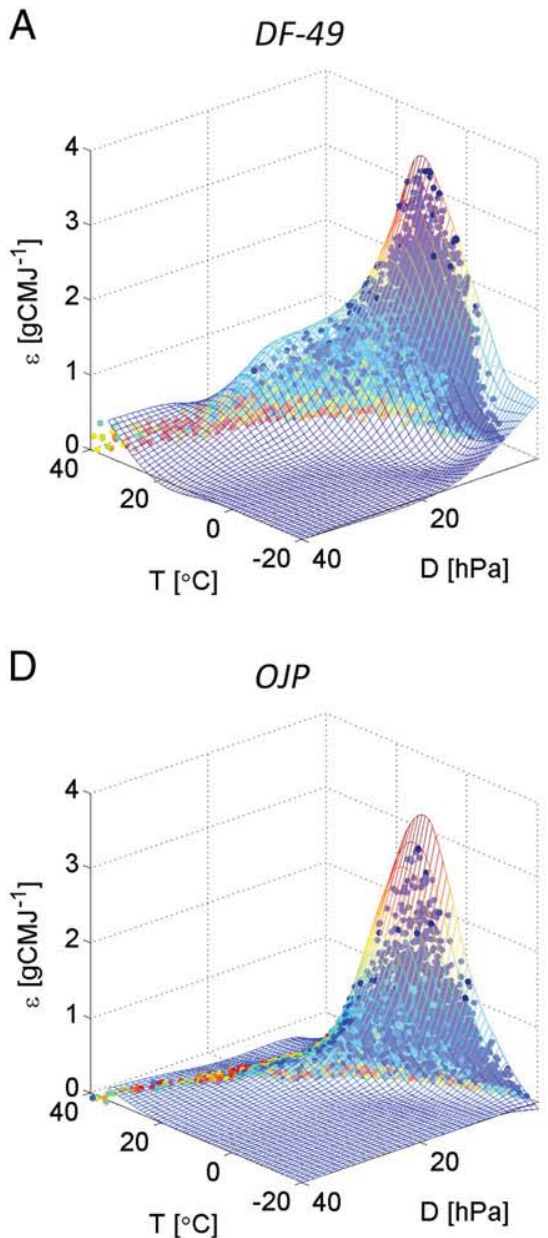

G

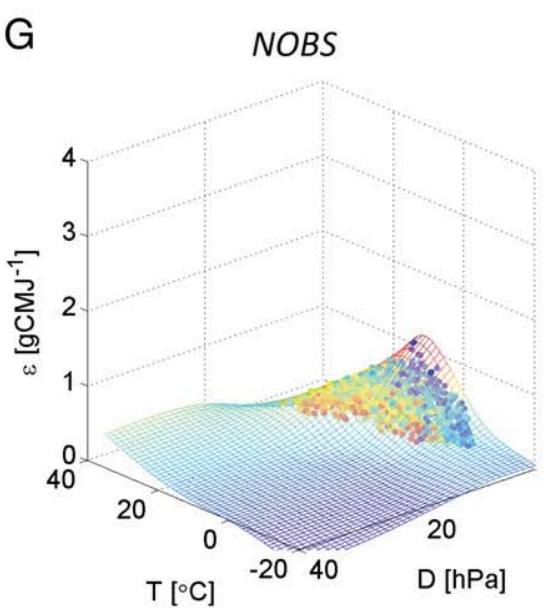

B

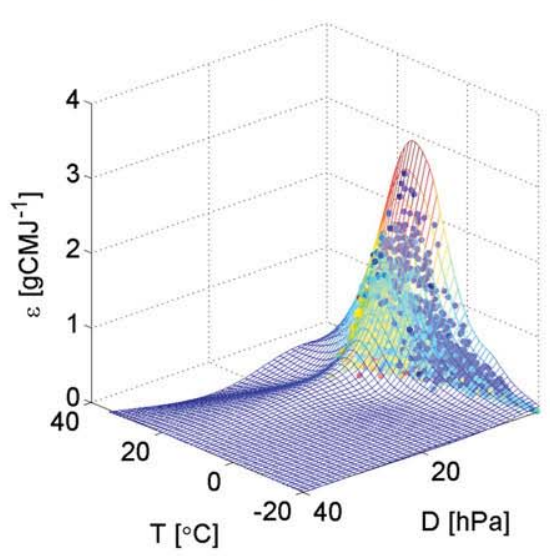

$E$

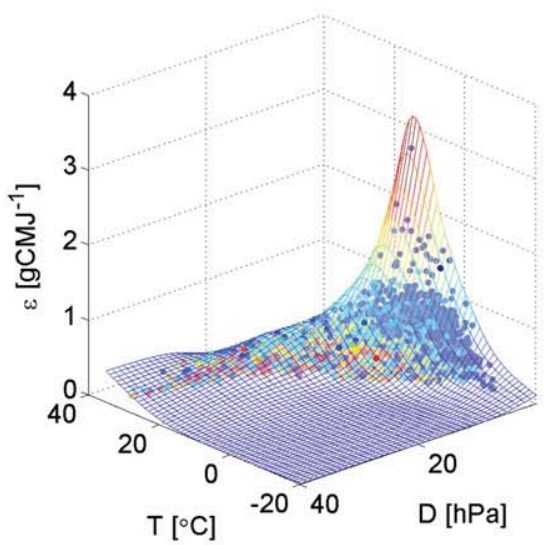

$\mathrm{H}$

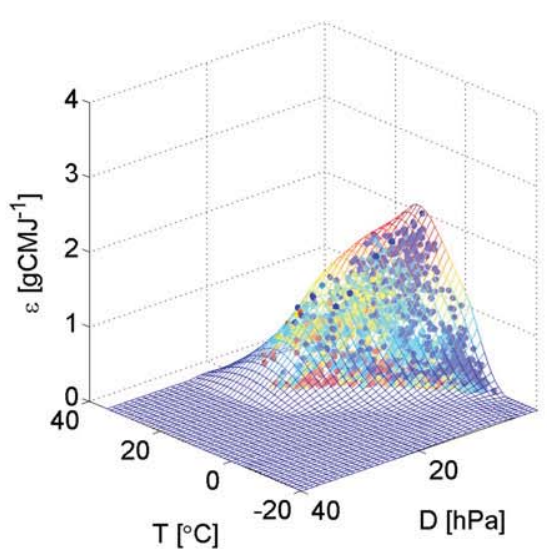

SOA
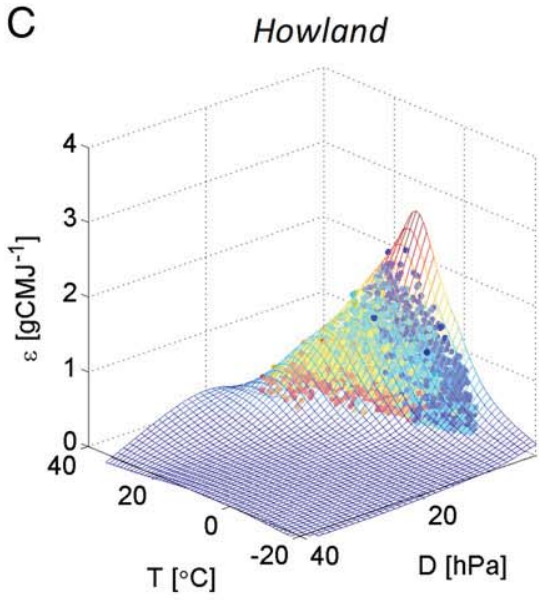

$\mathrm{F}$

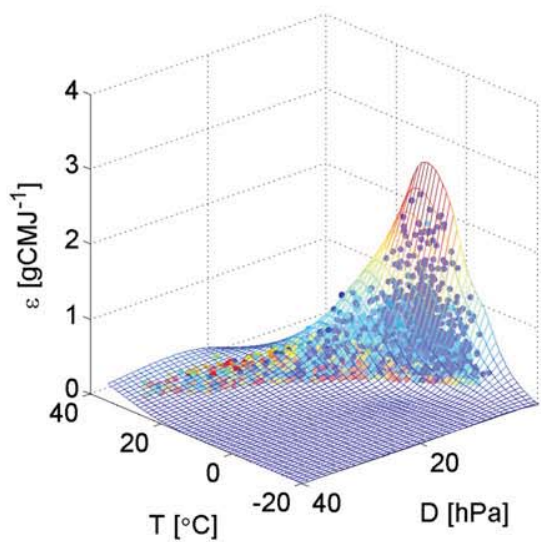

Fig. 3. Dependency of $\varepsilon$ on D and T using hourly EC-flux data (only daily data were available in cases of B, C and G) for 8 different tower sites. The 3D surface is showing the bounding envelope, the dots are the actual observations. The color code of the mesh corresponds to the different levels of $\varepsilon$, the color code of the observations corresponds to the level of PAR (dark $=$ low, bright $=$ high $)$. 

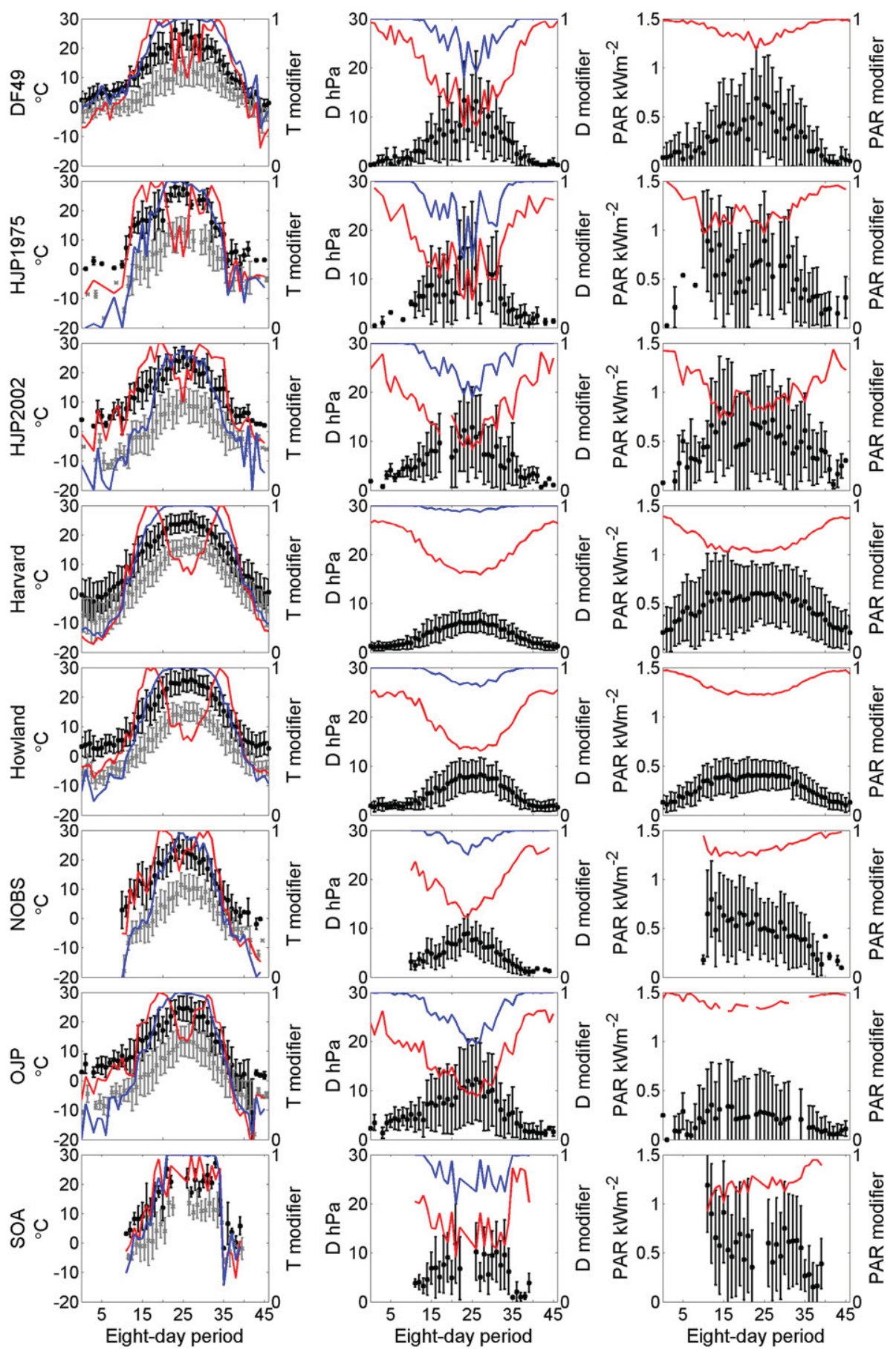

Fig. 4. Mean and standard deviation of minimum and maximum 8-day temperature, D and PAR at the 8 research sites and annual course of the T, D and PAR modifiers, shown in red. The T and D modifiers of the MODIS algorithm are shown in blue. The left column shows the temperature modifier, the central column represents the modifier for the vapor pressure deficit, and the right column shows the PAR modifier.

highlight the different levels of $\varepsilon$. The response function envelop reflects the maximum $\varepsilon$ inferred for a given temperature and water vapor pressure deficit. Our model assumes that all further reduction in $\varepsilon$ is caused by increases in PAR.

Fig. 4 shows a comparison between the meteorological response functions for D and T using the traditional approach and ours (Figs. 4 and 5 in Hall et al., this issue). The response functions presented in Fig. 4 are based on biological rationale and their coefficients were estimated by minimizing the difference between tower-measured GEP and model computed GEP. One year worth of data is shown for each site. The left column in Fig. 4 shows the minimum (gray) and maximum (black) temperature, here averaged over eight days for display purposes. The error bars in all columns represent the standard deviations around the means. The central column is showing variations in D (mean and standard deviation); the right column represents 8day variations in PAR (mean and standard deviation). The corresponding response functions of the MOD17 algorithm are shown in blue (right axis of the left and central columns), a response function of the model introduced in this study is shown in red. As it was shown in Fig. 6 of Hall et al. (this issue), $\varepsilon$ responses to T, D and PAR are not separable into multipliers because the $\varepsilon$ responses to T, D and PAR are interdependent. Consequently, the red lines in Fig. 4 show the 
A

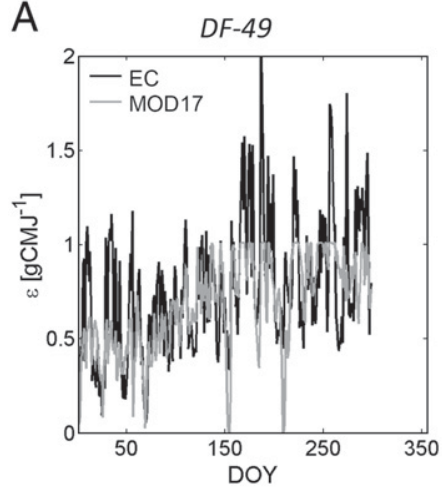

D

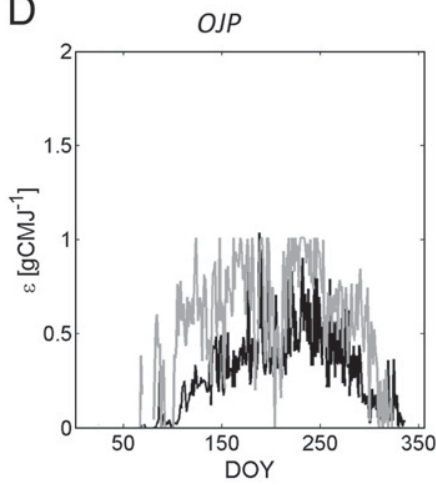

G

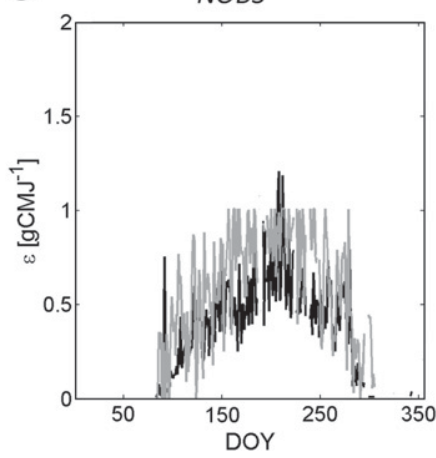

B

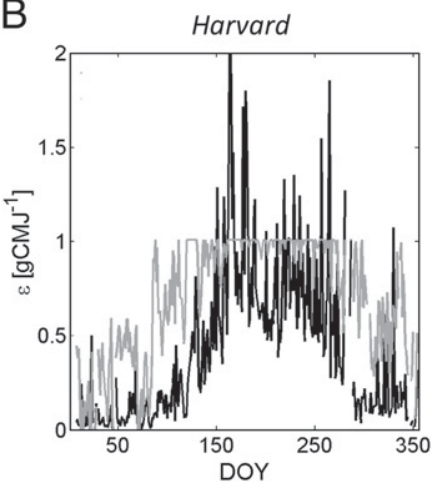

$\mathrm{E}$

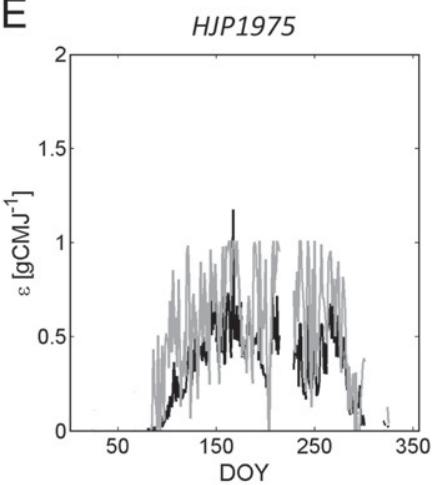

$\mathrm{H}$

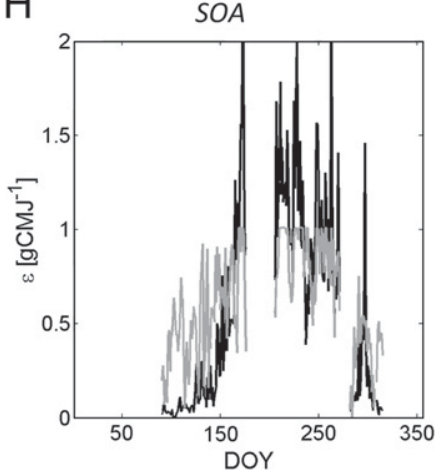

C

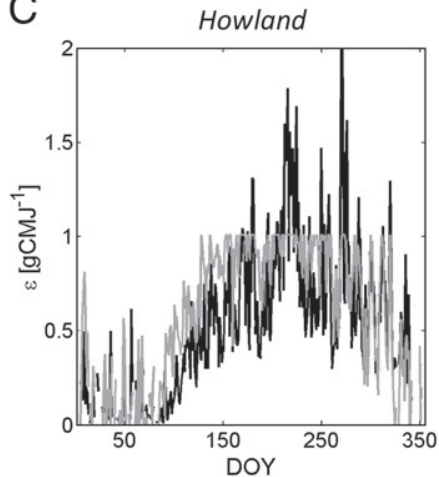

$\mathrm{F}$
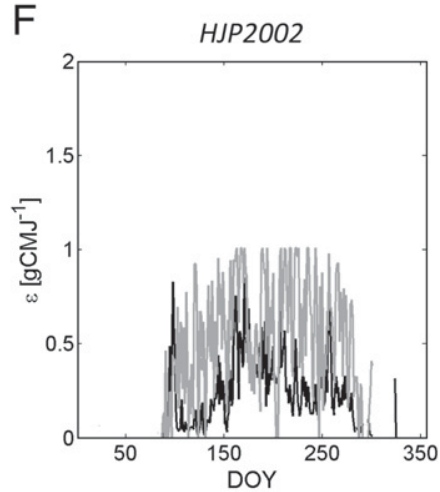

Fig. 5. Comparison between EC derived $\varepsilon$ (daily averages) and daily averaged estimates of $\varepsilon$ determined using the MOD17 approach for the 8 different flux tower sites.

response of the $\varepsilon$ modifier to one of the three variables with the other two fixed, when all other stresses are at a minimum (smallest possible reductions). The response functions for the MOD17 model and the model introduced in this study were computed from hourly observations of eddy flux data and then averaged over the eight day period for display purposes.

A clear seasonal signal was found at each site, however, seasonal differences were particularly strong at the three BOREAS sites, whereas the climate variability was smallest at the Coastal Douglas-fir (DF-49) site. When using the MOD17 algorithm, D limited photosynthesis only during short periods of the year, or not at all, as in case of the Harvard site.

The response functions observed from the MOD17 algorithm showed a largely temperature driven limitation to photosynthesis. During the beginning and the end of the season, the temperature responses of our model were similar to those shown for the MOD17 algorithm; however, our model yielded a significant reduction in $\varepsilon$ during mid summer, when temperatures were high. Our model also showed a much stronger reduction of the modeled photosynthesis due to $\mathrm{D}$ (driving stomatal conductance) when compared to the MOD17 algorithm, due to its non-linear character. The PAR-based reduction in photosynthetic efficiency was comparatively higher at the deciduous sites and mixed than at the coniferous sites due to the large amount of shading observed at the coniferous sites, causing an effective reduction in direct incident solar radiation. The PAR based response was strongest at the HJP 2002 site, which experienced almost no shading as a recently harvested, regenerating site.

Fig. 5 shows a comparison between tower-derived $\varepsilon$ and the efficiency modeled from environmental constraints using the MOD17 algorithm across the different research sites. The $\varepsilon_{\text {opt }}$ values were obtained from the MOD17 lookup table for the respective biome type. While the model captured some of the seasonal patterns shown in the eddy-flux data, values saturated at $\varepsilon_{\text {opt }}$ for notable parts of the growing season at most of the observed sites. The algorithm tended to overestimate $\varepsilon$, especially during the onset of the growing season and later in fall. The model also overestimated the boreal coniferous sites (Figure D, G) for most of the year. The differences in modeled $\varepsilon$ resulted in an overestimation of GEP for most sites, except DF-49. The RMSE between tower observations and modeled $\varepsilon$ values was $0.32 \mathrm{~g} \mathrm{C} \mathrm{MJ}^{-1}$ (DF-49), $0.40 \mathrm{~g} \mathrm{C} \mathrm{MJ}^{-1}$ (Harvard), $0.38 \mathrm{~g} \mathrm{C} \mathrm{MJ}^{-1}$ (Howland), $0.33 \mathrm{~g} \mathrm{C} \mathrm{MJ}^{-1} \quad$ (OJP), $0.38 \mathrm{~g} \mathrm{C} \mathrm{MJ}^{-1}$ (HJP1975), $0.32 \mathrm{~g} \mathrm{C} \mathrm{MJ}^{-1}$ (HJP2002), $0.32 \mathrm{~g} \mathrm{C} \mathrm{MJ}^{-1}$ (NOBS) and 

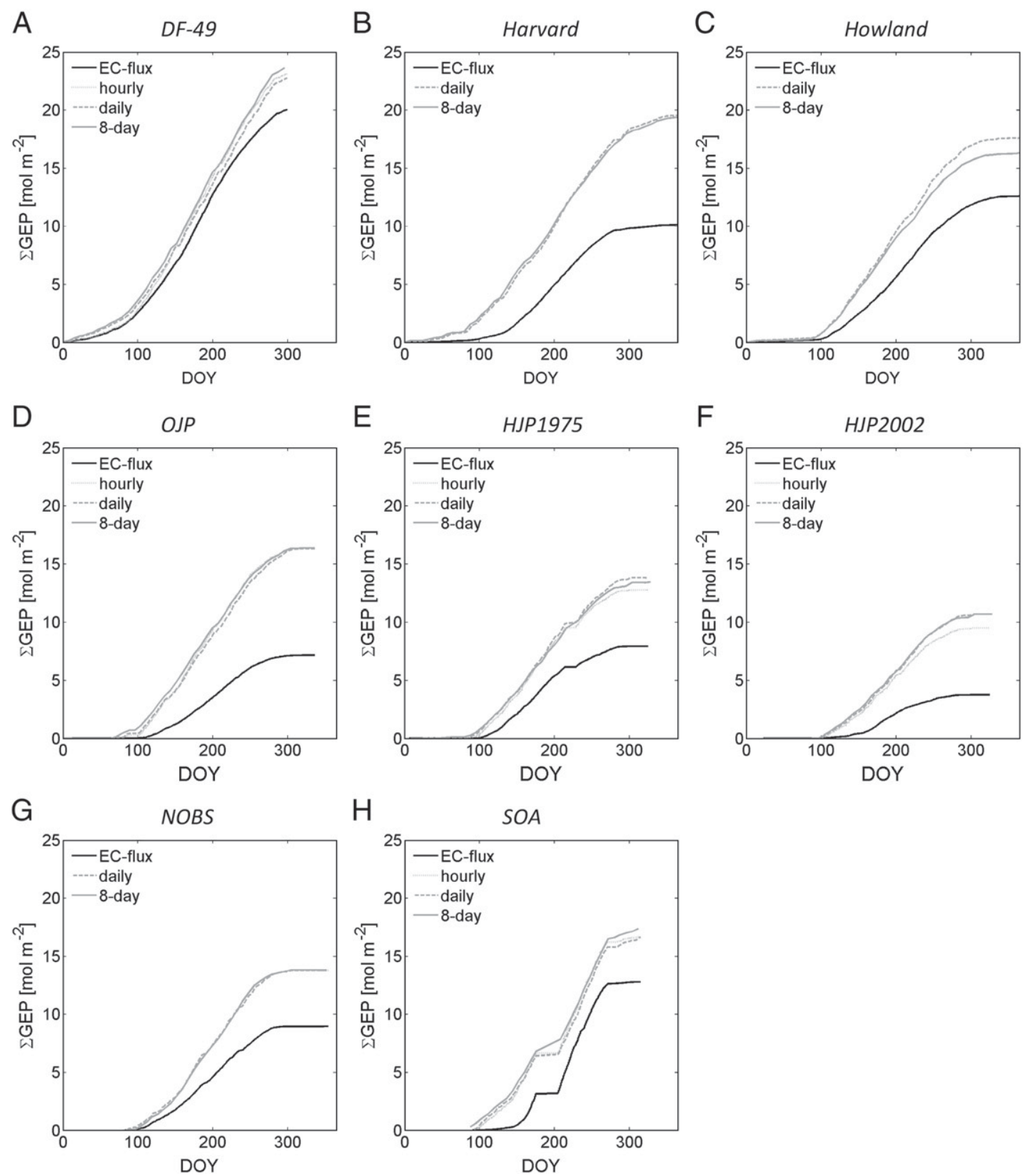

Fig. 6. Comparison between EC measured hourly GEP (only daily data were available in cases of B, C and G) and hourly, daily and 8-day averaged estimates of GEP determined using the MODIS approach for all flux tower sites. The y-axis shows the cumulative sum in GEP acquired for up to one year in length.

$0.25 \mathrm{~g} \mathrm{C} \mathrm{MJ}^{-1}$ (SOA). Fig. 6 shows a comparison of cumulative GEP estimated over one year as derived from the flux tower observations and the MOD17 algorithm. In order to compare the effects of different averaging techniques, data is shown for estimates of $\varepsilon$ made from hourly, daily and 8-day observations of $\mathrm{T}_{\mathrm{Min}}$ and $\mathrm{D}$. The results shown in Fig. 6 have been normalized by the number of observations made, in order to allow a direct comparison of the cumulative sums.

The use of non-linear response functions in combination with dynamic $\varepsilon_{\text {opt }}$ values inferred from satellite observations helped in increasing the accuracy of estimated $\varepsilon$ and GEP values considerably. Fig. 7 shows examples of $\varepsilon_{\text {opt }}$ values derived across the different study areas from model inversion of CHRIS/Proba observations. Three of the study sites (OJP, HJP 2002, and HJP1975) where all contained in one CHRIS/Proba scene (Fig. 7D). The size of the maps shown in Fig. 7 varies from site to site, as $\varepsilon_{\text {opt }}$ requires a stack of multi-angular CHRIS/Proba scenes to overlap in order to be able to infer PRI' (see Hilker et al., 2011 for details). The figure illustrates the spatial heterogeneity of the estimated $\varepsilon_{\mathrm{opt}}$ values at each of the sites. No multiple inferences of $\varepsilon_{\text {opt }}$ in time were made at this point, as most of the sites were limited by the availability of sufficient satellite data, and as a result all satellite images during the seasons displayed in Fig. 7 were used to derive $\varepsilon_{\text {opt }}$. However, the potentials of inferring multiple $\varepsilon_{\mathrm{opt}}$ throughout the seasons are illustrated by the example of the southern BOREAS area and shown in Fig. 10 (This site had 7 useful satellite images available throughout 2006 and 2007). Highest variability in $\varepsilon_{\text {opt }}$ was found at the most structurally diverse landscapes, especially the heavily logged area around the DF-49 site, but also at the southern Boreas site. Only moderate differences in CHRIS/Proba-inferred $\varepsilon_{\text {opt }}$ were found at the NOBS site, which is one of the more homogeneous sites under investigation as illustrated in Fig. 2. No CHRIS/Proba data were available for the SOA site.

A comparison between tower-derived $\varepsilon$ and the efficiency modeled using the non-linear responses are shown in Fig. 8. The $\varepsilon_{\text {opt }}$ 
A

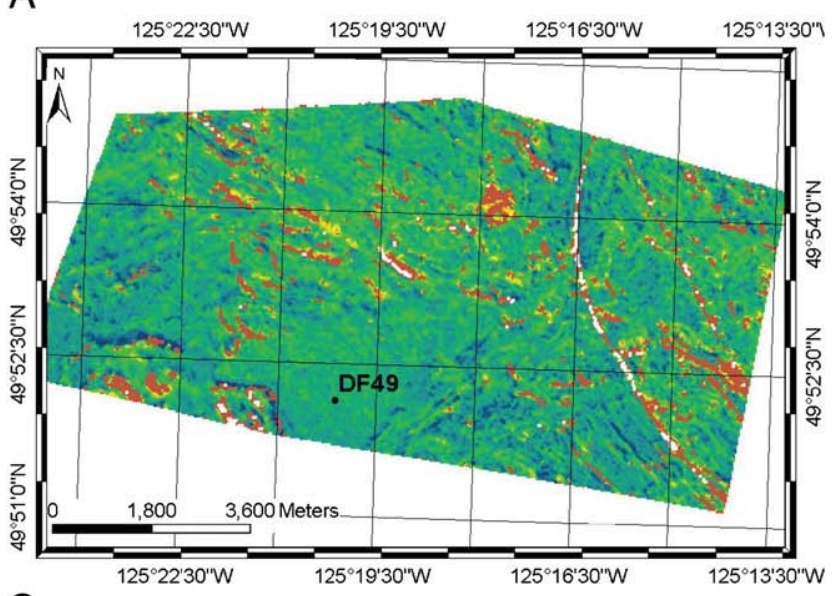

C

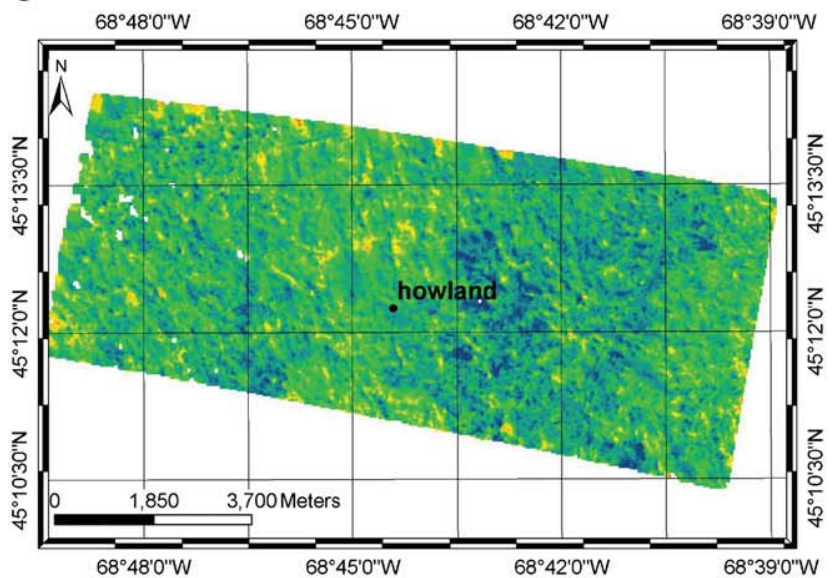

E

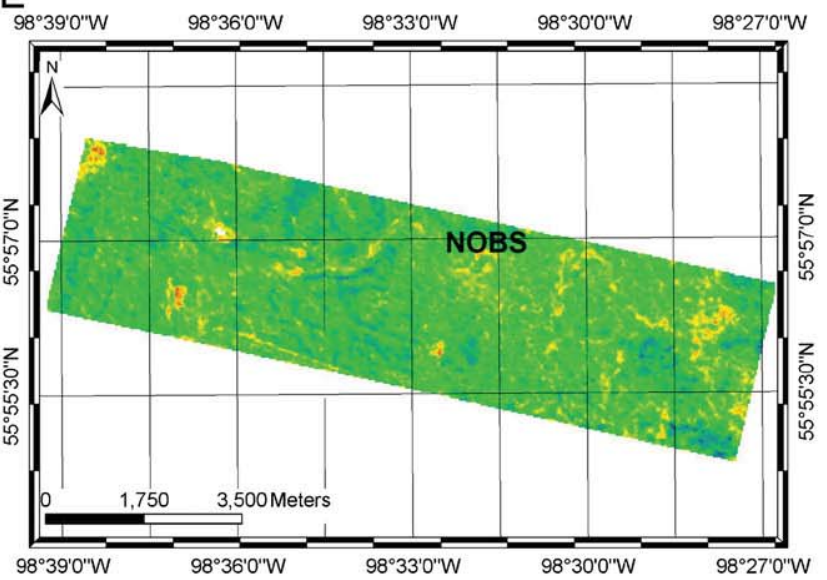

$\mathrm{B}$

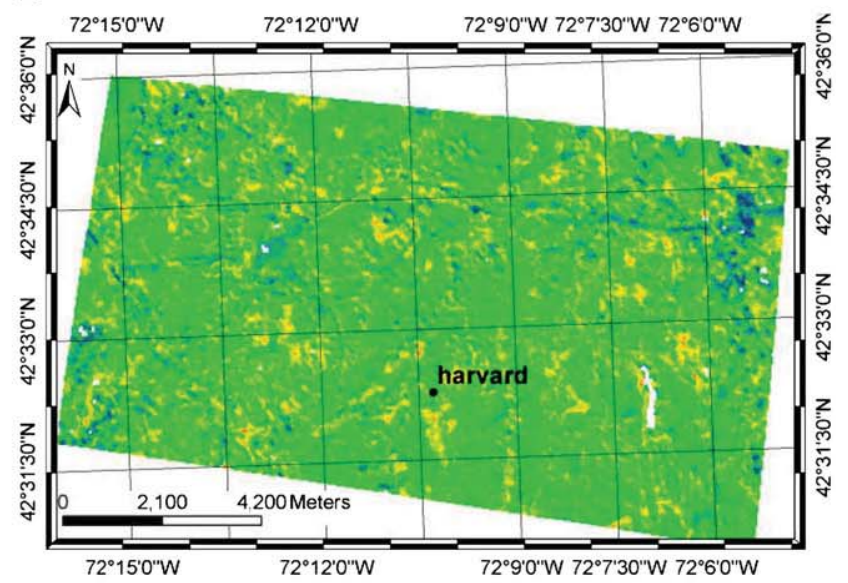

D

$104^{\circ} 48^{\prime} \mathrm{O}^{\prime \prime} \mathrm{W} 104^{\circ} 45^{\prime} \mathrm{O}^{\prime \prime} \mathrm{W} 104^{\circ} 42^{\prime} \mathrm{O}^{\prime \prime} \mathrm{W} 104^{\circ} 39^{\prime} \mathrm{O}^{\prime \prime} \mathrm{W} 104^{\circ} 36^{\prime} \mathrm{O}^{\prime \prime} \mathrm{W} 104^{\circ} 33^{\prime} \mathrm{O}^{\prime \prime} \mathrm{W} 104^{\circ} 30^{\prime} \mathrm{O}^{\prime \prime} \mathrm{W}$

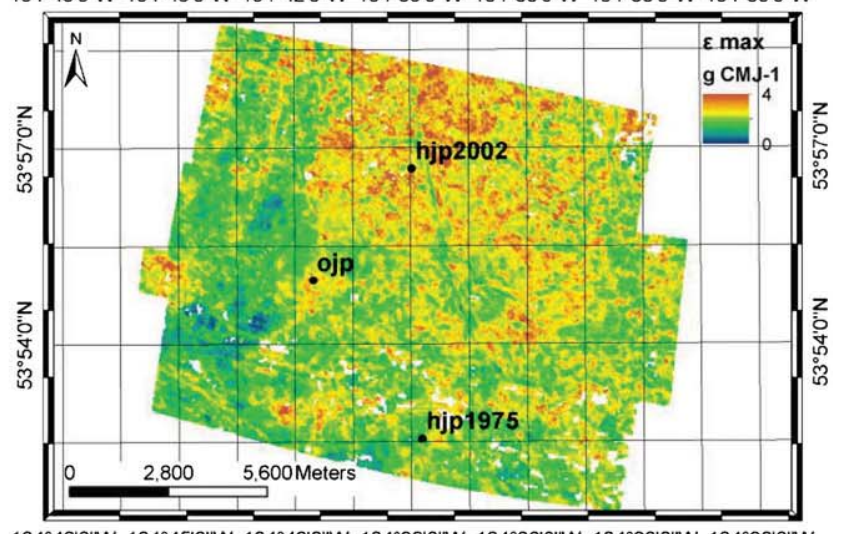

$104^{\circ} 48^{\circ} \mathrm{O}^{\prime} \mathrm{W} 104^{\circ} 45^{\circ} \mathrm{O}^{\prime \prime} \mathrm{W} 104^{\circ} 42^{\prime} \mathrm{O}^{\prime \prime} \mathrm{W} 104^{\circ} 39^{\circ} \mathrm{O}^{\prime \prime} \mathrm{W} 104^{\circ} 36^{\circ} \mathrm{O}^{\prime \prime} \mathrm{W} 104^{\circ} 33^{\prime} \mathrm{O}^{\prime \prime} \mathrm{W} 104^{\circ} 30^{\circ} \mathrm{O}^{\circ} \mathrm{W}$

Fig. 7. Examples of $\varepsilon_{\text {opt }}$ values derived across the different study areas from model inversion of CHRIS/Proba observations. (A: DF-49, B: Harvard Forest, C: Howland Forest, D: OJP, HJP and HJP 2002, E: NOBS).

values were obtained from CHRIS/Proba as presented in Fig. 7 and averaged over an area of $3 \times 3$ pixels around the tower to include about $80 \%$ of the daytime flux footprint (Hilker et al., 2008a). In case of the SOA site, the maximum observed $\varepsilon$ as determined by the eddy covariance system was used as a surrogate (top $1 \%$ of the data). The higher $\varepsilon_{\text {opt }}$ values prevented the model from saturating thus allowing it to capture most of the variability in $\varepsilon$ throughout the season. The RMSE between tower observations and modeled $\varepsilon$ values was $0.24 \mathrm{~g} \mathrm{C} \mathrm{MJ}^{-1}$ (DF-49), $0.20 \mathrm{~g} \mathrm{C} \mathrm{MJ}^{-1}$ (Harvard), $0.23 \mathrm{~g} \mathrm{C}$ $\mathrm{MJ}^{-1}$ (Howland), $0.17 \mathrm{~g} \mathrm{C} \mathrm{MJ}^{-1}$ (OJP),0.16 g C MJ ${ }^{-1}$ (HJP1975),
$0.12 \mathrm{~g} \mathrm{C} \mathrm{MJ}^{-1}$ (HJP2002), $0.15 \mathrm{~g} \mathrm{C} \mathrm{MJ}^{-1}$ (NOBS) and $0.15 \mathrm{~g} \mathrm{C} \mathrm{MJ}^{-1}$ (SOA). The non-linear response also increased the range in variability in $\varepsilon$ thereby allowing it to follow the EC observed values more closely. As a result, the new model yielded more realistic estimates of GEP across the 8 different research sites with the errors in cumulate GEP being notably reduced compared to Fig. 6 (Fig. 9).

Fig. 10 shows a time series of $\varepsilon_{\text {opt }}$ values inferred for the example of the southern Boreas study area between 2006 and 2007. $\varepsilon_{\text {opt }}$ was derived from model inversion using three consecutive CHRIS/Proba scenes in a "moving window" approach, the dates provided in 
A
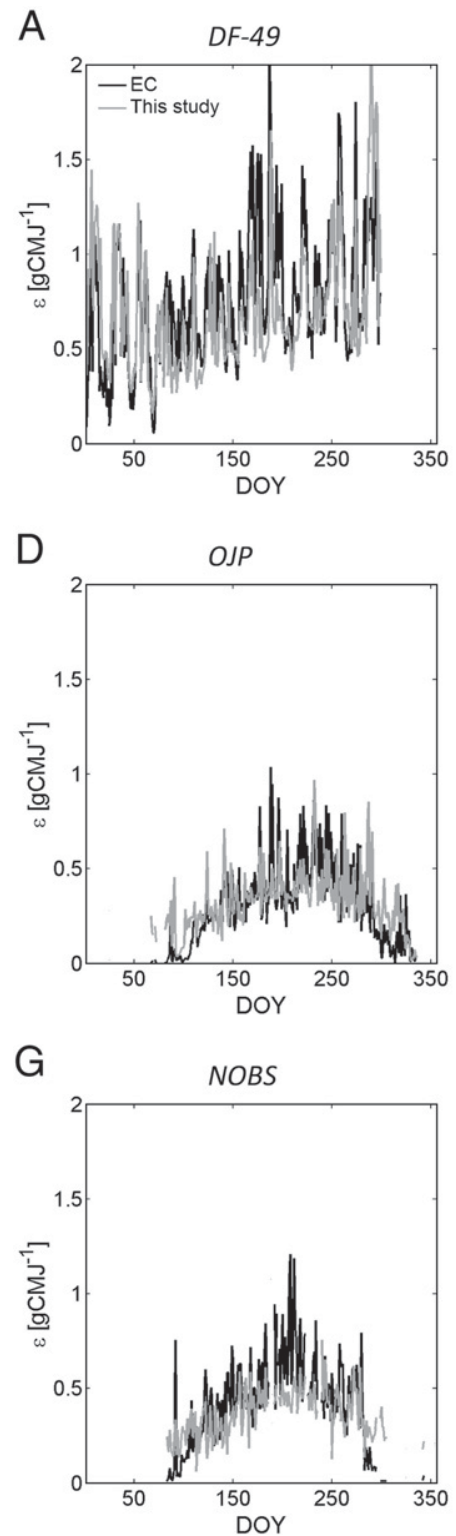

$\mathrm{B}$

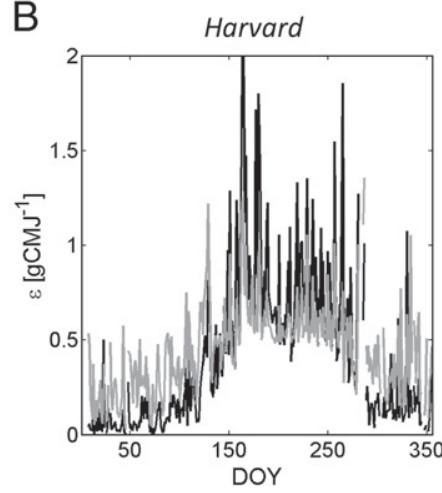

E

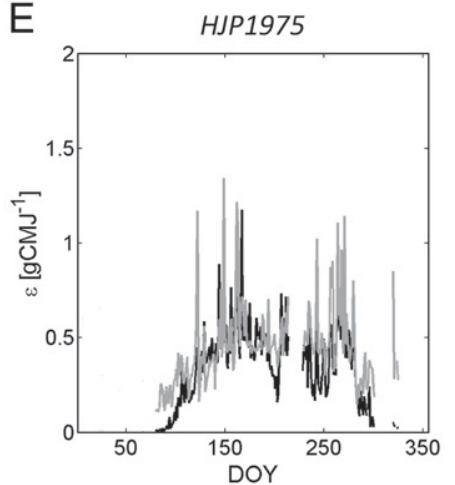

$\mathrm{H}$

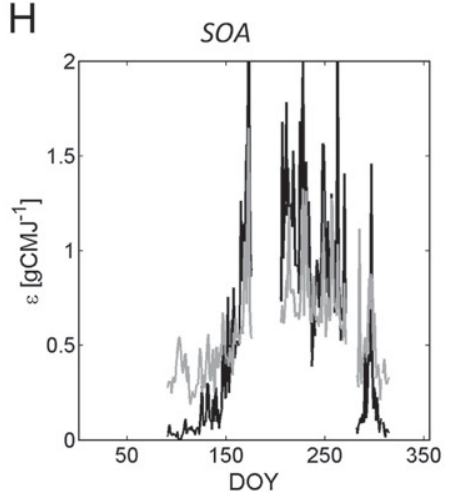

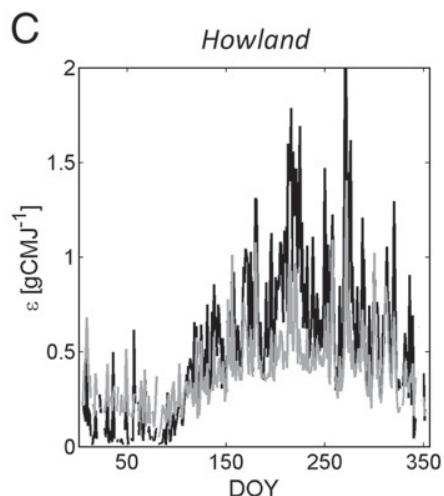

$\mathrm{F}$

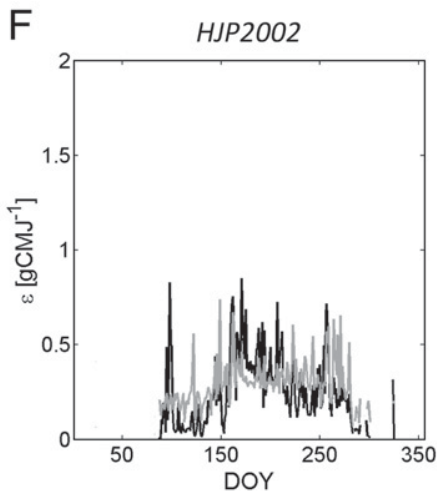

Fig. 8. Comparison between EC derived $\varepsilon$ (daily averages) and daily averaged estimates of $\varepsilon$ determined using the approach introduced in this study for the 8 flux tower sites.

Fig. 10 are representing the date of the first of three consecutive images. Please note that the spatial extend of the maps varied from time step to time step as the common area of overlap was different for each acquisition. The figure illustrates a consistent spatial pattern of $\varepsilon_{\text {opt }}$ across the southern Boreas study area between mid 2006 and mid 2007. While the temporal frequency of observations is not enough to allow a comprehensive analysis of the seasonal effects on $\varepsilon_{\text {opt }}$, some seasonal patterns could be observed. For instance, the $\varepsilon_{\text {opt }}$ value for the OJP tower decreased consistently from $2.7 \mathrm{~g} \mathrm{C} \mathrm{MJ}^{-1}$ in June 4, 2006 to $2.4 \mathrm{~g} \mathrm{C} \mathrm{MJ}^{-1}$ in October 2006 and went back up to $2.7 \mathrm{~g} \mathrm{C} \mathrm{MJ}^{-1}$ in August 2007. Over the same time period, $\varepsilon_{\text {opt }}$ values for the area around the HJP 2002 tower showed a slight, but consistent decrease from $2.1 \mathrm{~g} \mathrm{C} \mathrm{MJ}^{-1}$ to $1.9 \mathrm{~g} \mathrm{C} \mathrm{MJ}^{-1}$ and went back up to $2.3 \mathrm{~g} \mathrm{C} \mathrm{MJ}^{-1}$ in August 2007.

\section{Discussion}

This study introduced and verified a, physiologically grounded model to infer landscape-level photosynthesis from data assimilation of meteorological observations and multi-angular satellite images.
The technique previously developed in Hall et al. (2011) and Hilker et al. (2011) allowed us, for the first time, to observe instantaneous $\varepsilon$ and therefore GEP directly from space (Hilker et al., 2011) across a wide range of forested ecosystems. The intention of the present work was to demonstrate how such information could be used in a data assimilation scheme to improve global estimates of GEP. The lack of spatial heterogeneity in biome specific $\varepsilon_{\text {opt }}$ values has previously been identified as a significant drawback (Goulden et al., 1996) of the MODIS MOD17 approach (Running et al., 2004). The use of multi-angular satellite observations may help to overcome some of these limitations, by 1 ) allowing a spatially explicit mapping of $\varepsilon_{\text {opt }}$ across the landscape and 2 ) allowing $\varepsilon_{\text {opt }}$ to vary over time, at least in the presence of sufficient spaceborne observations.

The non-linear response functions based on Bernacchi et al. (2002) and Jarvis (1976), but coupled as multivariate functions, yielded a notable improvement over the previous techniques based on linear datasets, at least for the sites investigated in this study. The non-linear model showed better results in capturing the seasonal variability in $\varepsilon$ (Figs. 5 and 7), whereas the linear functions tended to overestimate $\varepsilon$ during the early and late season and saturated for 

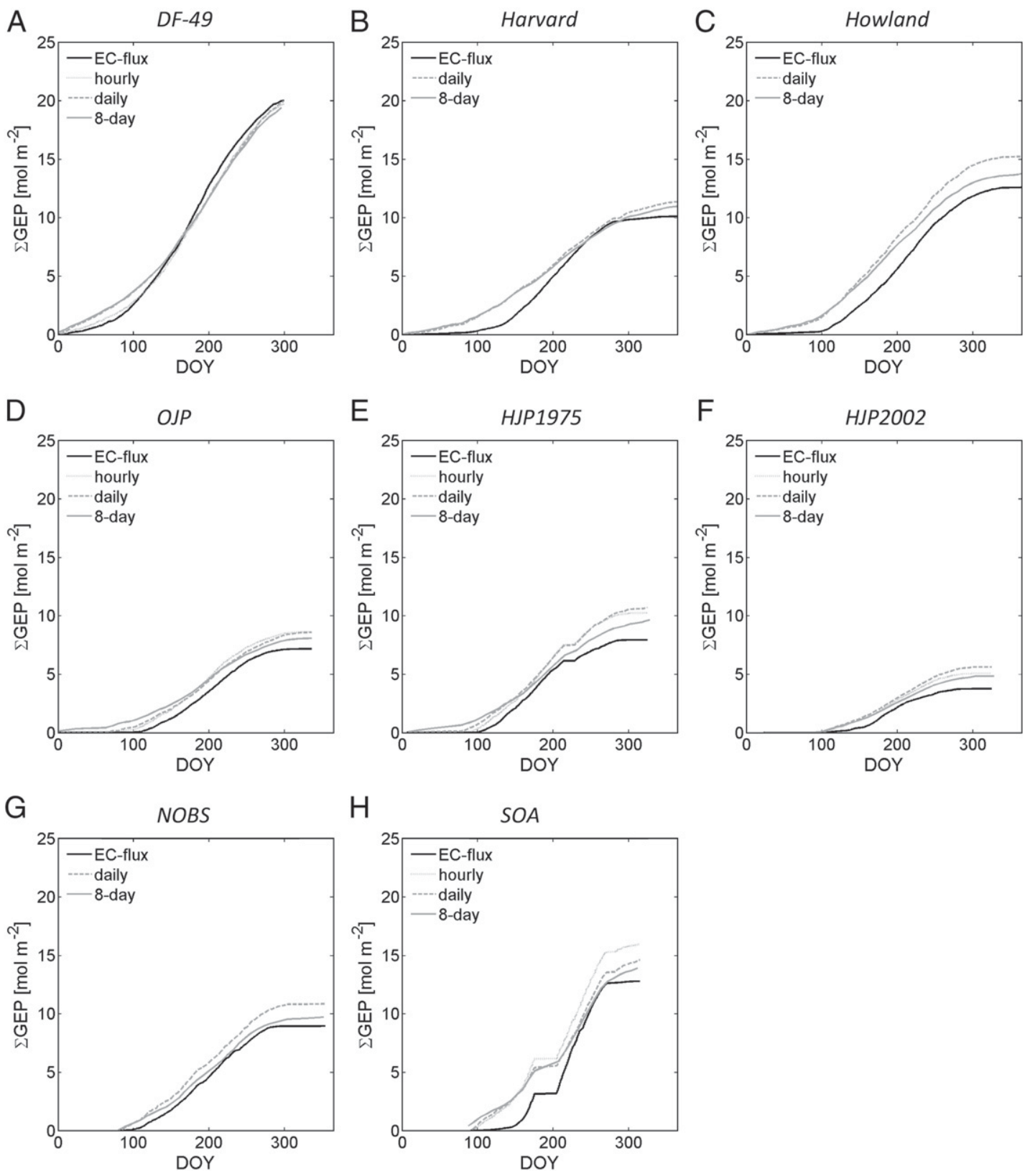

Fig. 9. Comparison between EC measured hourly GEP (only daily data were available in cases of B, C and G) and hourly, daily and 8-day averaged estimates of GEP determined using the approach introduced in this study for 8 different flux tower sites. The $y$-axis shows the cumulative sum in GEP acquired for up to one year in length.

much of the summer season (Fig. 5) (compare also Turner et al., 2003), as little or no limitations were imposed by either D or temperature. The use of the non-linear response functions yielded a sharper limitation of $\varepsilon_{\mathrm{opt}}$, as a result of $\mathrm{D}, \mathrm{T}_{\mathrm{min}}$ and PAR. Additionally, our model response to above optimal temperature conditions resulted in further reductions during the summer across most of the sites (perhaps with the exception of the northern BOREAS study region, NOBS, see Fig. 4) where warmer temperatures may be advantageous. By down-regulating photosynthesis with PAR, our multivariate response function also had a notable impact on $\varepsilon$, especially at the deciduous and clear-cut sites. The stronger response with respect to environmental stress factors allowed for a more realistic $\varepsilon_{\text {opt }}$ which was close to the maximum $\varepsilon$ observed by the eddy covariance data at the eight sites (compare the peaks of modeled and observed values in Fig. 3). While Fig. 4 gives an impression of the differences in the response functions used in both approaches, it should be noted that the responses introduced in this model are multivariate and consequently, the functions in Fig. 4 only represent the reductions which are imposed if all other stresses are zero (compare Fig. 3). A direct comparison between the reduction levels of both algorithms is therefore difficult and should be viewed with caution as no interaction between the photosynthesis limiting factors is allowed in the MODIS approach. The differences in modeled, cumulative GEP as shown in Figs. 6 and 8 demonstrate the advantages of the nonlinear, multivariate, physiologically-based responses. Specifically, the deviations in cumulative GEP are a direct result of the differences in which $\varepsilon$, as the estimates of $f_{\text {par }}$ and PAR were identical for ECmeasured, linearly and non-linearly obtained models.

While the non-linear functions introduced in Hall et al. (this issue) yielded more realistic estimates of $\varepsilon$ and therefore GEP, they also added more complexity. For instance, the shape parameters of the curves were derived from eddy covariance observations using model inversion, which requires a certain level of availability of such data across the landscape. Such data are currently available 
A

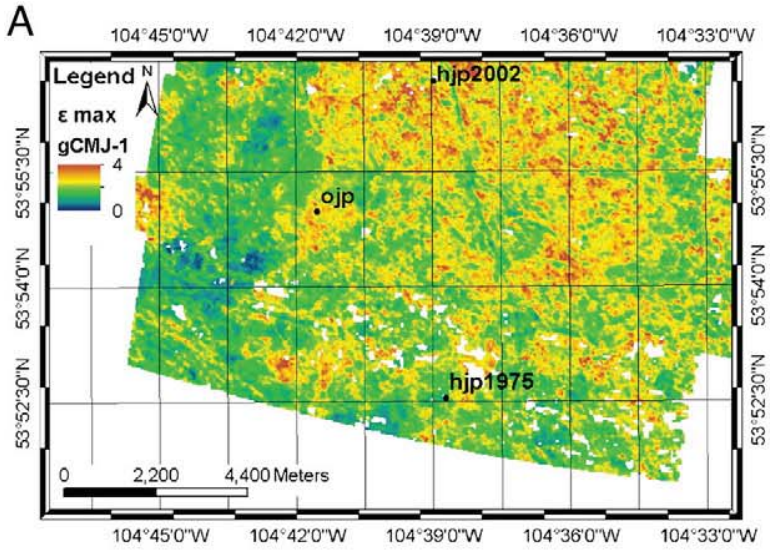

C

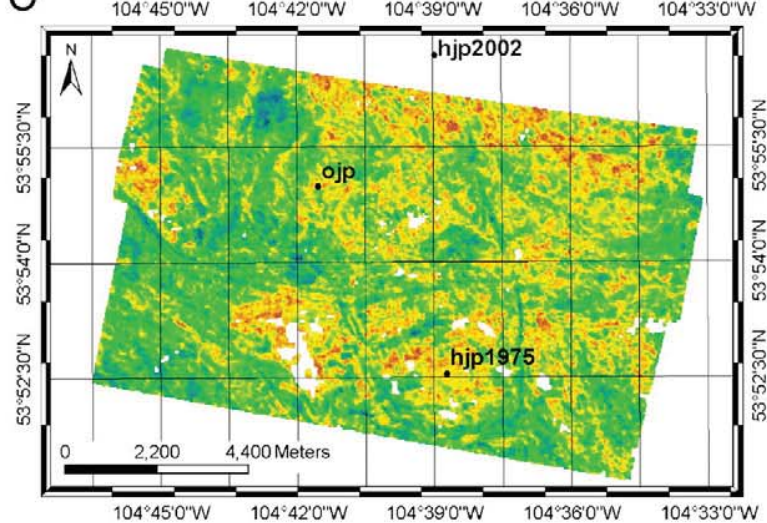

E

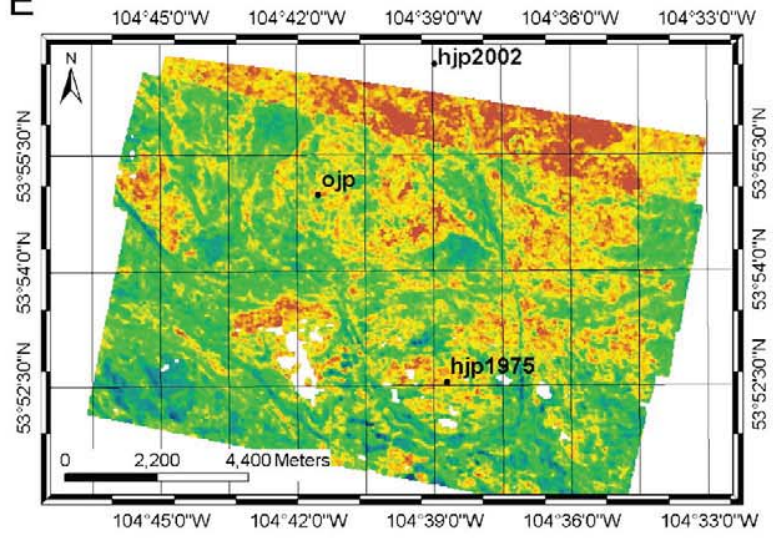

B

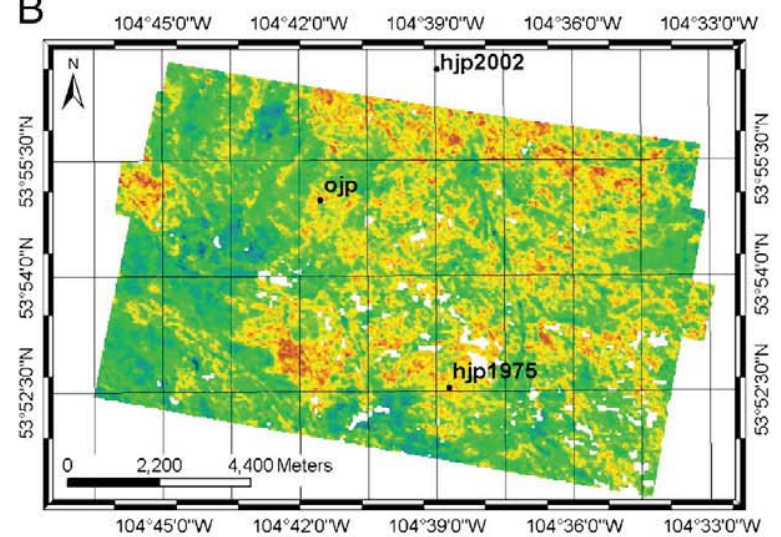

$\mathrm{D}$

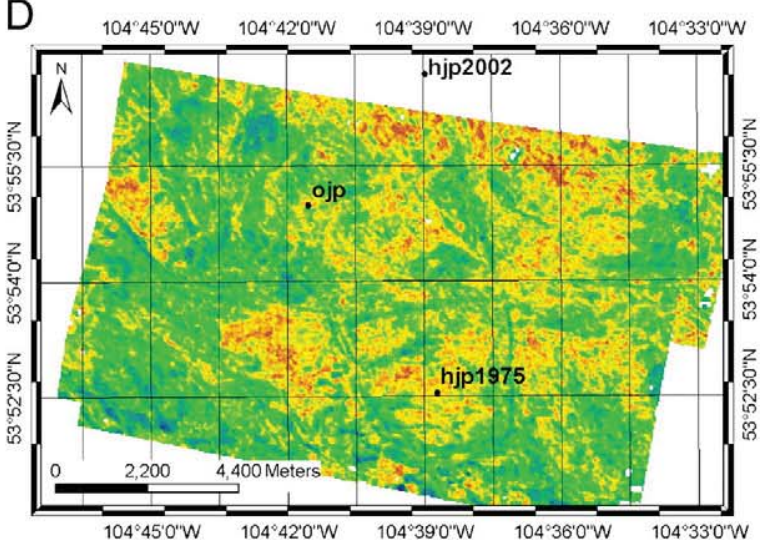

$\mathrm{F}$

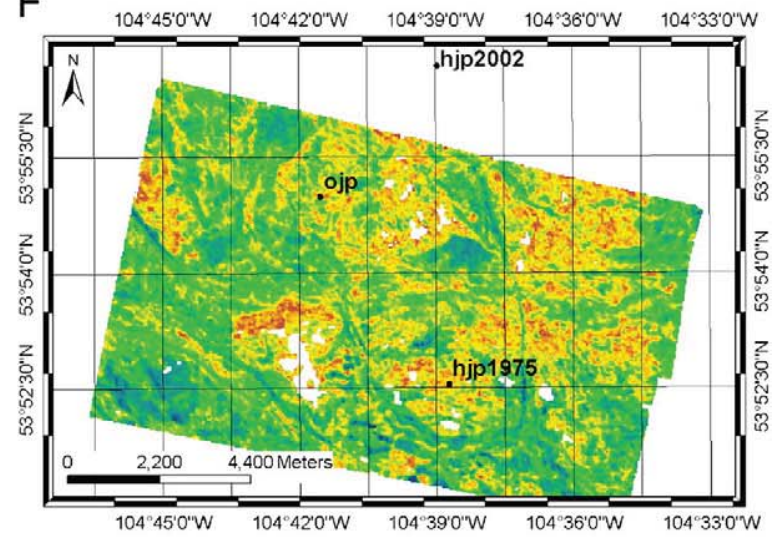

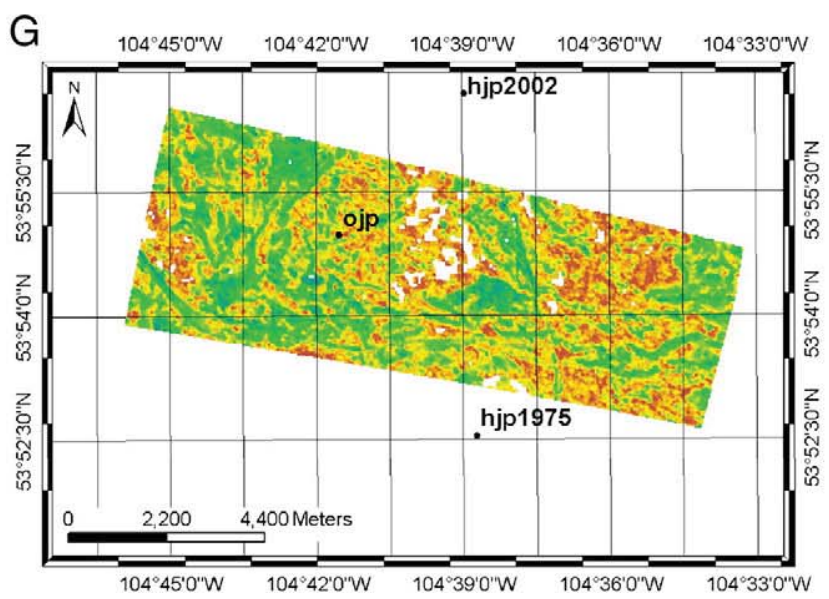

Fig. 10. Time series of $\varepsilon_{\text {opt }}$ values derived from CHRIS/Proba scenes over the southern BOREAS study area. The dates (DOY) of observations were 2006/155 (A), 2006/197 (B), 2006/ 240 (C), 2006/274 (D), 2006/300 (E), 2007/187 (F) and 2007/214 (G). 
through flux tower networks, assuming that the functional form of the stress response function is identical for all vegetation types across a given area or biome (note however, the quantity is still driven by $\varepsilon_{\text {opt }}$, which is different for every $30 \times 30 \mathrm{~m}$ pixel). This assumption is reasonable to a first approximation, as these responses are mainly shaped by evolutionary processes and are therefore largely a result of climate adaptations. As a result, the functional form (not the magnitude) of the response functions can be assumed to be relatively invariant, at least across climatically similar regions. Limitations are faced with respect to differences in elevation, as higher regions, even if in spatial proximity, can vary significantly in climate. Similar assumptions, however, are also made in case of the MODIS MOD17 algorithm as minimum and maximum $\mathrm{T}_{\min }$ and $\mathrm{D}$ levels are determined for each biome type (Heinsch et al., 2006; Running et al., 2004; Zhao et al., 2005).

Arguably, one of the most significant advantages of the technique introduced in this study is the inference of a spatially explicit, temporally dynamic $\varepsilon_{\text {opt }}$ from the CHRIS/Proba imagery. The maps shown in Fig. 9 illustrate the heterogeneity in $\varepsilon_{\text {opt }}$, even across the relatively small study areas. These differences are largely a result of changes in canopy structure and illustrate the need for an enhanced mapping of photosynthesis. The heterogeneity was largest at the coniferous sites (especially the southern BOREAS, but also the DF-49 site) as $\varepsilon$ in conifers is heavily driven by shadow fractions (Hilker et al., $2008 \mathrm{~b}, 2010 \mathrm{a})$. The high $\varepsilon_{\text {opt }}$ values in Fig. 7a are due to a lack of variation in shadow fractions at clear cut areas around the DF-49 site and present a limitation of the approach introduced in Hilker et al. (2011) and Hall et al. (2011): The satellite based technique is using the relationship between PRI and $\alpha_{s}$ to obtain a generic function of $\varepsilon$. This requires a sensor to observe vegetation under a certain range of $\alpha_{\mathrm{s}}$, which may not be available at less structured, herb and grass dominated areas. In such cases, it may be possible to base such observations primarily on PRI as the structure of these ecotones is much simpler, however, further study will be required to address this issue and also to investigate its significance with respect to terrestrial carbon budgets at a landscape scale.

The time series of $\varepsilon_{\text {opt }}$ values which were derived from CHRIS/ Proba data acquired between June 2006 and July 2007 illustrates the potential for a temporally dynamic inference of $\varepsilon_{\text {opt }}$ from satellite observations. Little variation was found in $\varepsilon_{\text {opt }}$ throughout the observed time period which could suggest that most of the seasonal variability at this site was driven by changes in D, T and PAR. However, these findings have to be interpreted with caution, as no off-season images were available and the temporal density of the existing time series is too sparse to show conclusive evidence. In addition, we required multiple observation dates to infer $\varepsilon_{\text {opt }}$ from model inversion (Hall et al., this issue; in this study we chose 3 consecutive dates). As a result, each of the maps shown in Fig. 10 represents 1 to 6 months of data thereby potentially smoothing some of the seasonal patterns that might exist. Due to data limitations, the observations used in this study, reflect relatively "normal" years, more variability, also in LAI, would be expected when observing extreme events, such as severe drought stresses and further research may be required to assess the algorithms performance under these circumstances. It is expected that $\varepsilon_{\text {opt }}$ would be greatly reduced and further reductions due to $D$ $\mathrm{T}$ and PAR would largely prevent photosynthesis.

For model inversion, $\varepsilon_{\text {opt }}$ was limited to $4 \mathrm{~g} \mathrm{C} \mathrm{MJ}^{-1}$ based on previous, tower obtained findings (Schwalm et al., 2006). While we found that this value was a good threshold for forested ecosystems around the tower sites, higher thresholds may be defined for vegetation with the potential for higher $\varepsilon_{\text {opt }}$ values. For instance, some of the harvested or disturbed areas in Fig. 7A and D show $\varepsilon_{\text {opt }}$ values of close to $4 \mathrm{~g} \mathrm{C} \mathrm{MJ}^{-1}$. Furthermore, $\mathrm{D}$ and $\mathrm{T}$ were assumed to be constant across a CHRIS/Proba scene. While this is probably reasonable to a first approximation, it should be noted that both variables will vary with vegetation type and also with elevation, and consequently, higher spatial resolution observations of temperature and humidity would be helpful to address this concern.

One of the biggest limitations of the algorithm presented in this study is the lack of suitable satellite data. To date, CHRIS/Proba is the only satellite in orbit that acquires PRI data from multiple view angles along track. The instrument, does not obtain data globally and, as a result, images exist for a very limited number of predefined test sites. The images are also not freely available, which further restricts its use. This lack of observations may result in limited possibilities for inferring $\varepsilon_{\text {opt }}$ at regular intervals throughout a growing season. As a result, the model may under-represent the seasonal effects of photosynthesis (as shown around DOY 200 in Fig. 8C and $\mathrm{G}$ ). Hilker et al. (2011) also identified a number of issues with existing satellite data such as the lack of a suitable atmospheric correction algorithm for multi-angular CHRIS/Proba data and a poor geo-location of the instrument. Our previous work has shown that some of these challenges could be overcome (Hilker et al., 2009b; Lyapustin et al., 2007); and Hall et al. (2011) showed that despite these limitations a meaningful retrieval of $\varepsilon$ is still possible. However, at this current stage, the limitations existing with CHRIS/Proba data prevent it from being used routinely. Consequently, the approach introduced in this study needs to be seen more as demonstration and as a motivation for developing a MISR-like space mission to enable direct space borne observations of $\varepsilon$; used in a data assimilation scheme to obtain spatially contiguous and temporally continuous estimates of vegetation photosynthesis.

While CHRIS/Proba data cannot be used in an operational sense, this satellite platform provides a unique opportunity to further test and develop the technique described in this study. At this point in its development we feel that the approach may be mature enough to study the relationship among vegetation light use efficiency, climate and edaphic factors over transects with variations in these factors. A new, multi-angular satellite sensor, as proposed in Hall et al. (2011), which uses 5 carefully selected wavebands to obtain $f_{\text {par }}$ from NDVI and $\varepsilon$ from PRI (plus one band for atmospheric correction) would allow us to apply a technique such as applied in this study globally. In addition, if satellite data was available on a regular basis, this would also overcome the limitations of inferring the shape parameters of the response curves from flux tower observations as they too could be directly obtained from space.

\section{Conclusion}

This study has demonstrated that spatially contiguous and temporally continuous estimates of $\varepsilon$ can yield dramatically enhanced estimates of plant photosynthesis. We have shown that $\varepsilon$ varies greatly in both space and time and therefore requires comprehensive modeling and sophisticated measurement techniques. The availability of multi-angular satellite data to infer instantaneous $\varepsilon$ on a routinely basis from space would allow us obtain more realistic estimates of vegetation carbon uptake through data assimilation and would therefore be a significant contribution to closing the terrestrial carbon cycle.

\section{Acknowledgments}

The ESA CHRIS/Proba images were provided by Dr. David G. Goodenough, Dr. Ray Merton, and Dr. Mathias Kneubühler, all principal investigators of the Evaluation and Validation of CHRIS (EVC) Project. The Center for Remote Sensing and Department of Geography at Boston University are thanked for provision of the GOMS model. Partial funding for this study was provided by NASA's Terrestrial Ecology Program managed by Dr. Diane Wickland. This research is also partially funded by the Canadian Carbon Program, the Natural Sciences and Engineering Research Council of Canada (NSERC) and BIOCAP, and an NSERC-Accelerator grant to NCC. 


\section{References}

Amiro, B. D., Barr, A. G., Black, T. A., Iwashita, H., Kljun, N., McCaughey, J. H., et al. (2006). Carbon, energy and water fluxes at mature and disturbed forest sites, Saskatchewan, Canada. Agricultural and Forest Meteorology, 136, 237-251.

Baldocchi, D. D. (2003). Assessing the eddy covariance technique for evaluating carbon dioxide exchange rates of ecosystems: Past, present and future. Global Change Biology, 9, 479-492.

Barr, A. G., Black, T. A., Hogg, E. H., Kljun, N., Morgenstern, K., \& Nesic, Z. (2004). Interannual variability in the leaf area index of a boreal aspen-hazelnut forest in relation to net ecosystem production. Agricultural and Forest Meteorology, 126, 237-255.

Bergeron, O., Margolis, H. A., Black, T. A., Coursolle, C., Dunn, A. L., Barr, A. G., et al. (2007). Comparison of carbon dioxide fluxes over three boreal black spruce forests in Canada. Global Change Biology, 13, 89-107.

Bernacchi, C. J., Portis, A. R., Nakano, H., von Caemmerer, S., \& Long, S. P. (2002). Temperature response of mesophyll conductance. Implications for the determination of Rubisco enzyme kinetics and for limitations to photosynthesis in vivo. Plant Physiology, 130, 1992-1998.

Black, T. A., Denhartog, G., Neumann, H. H., Blanken, P. D., Yang, P. C., Russell, C., et al. (1996). Annual cycles of water vapour and carbon dioxide fluxes in and above a boreal aspen forest. Global Change Biology, 2, 219-229.

Buck, A. L. (1981). New equations for computing vapor-pressure and enhancement factor. Journal of Applied Meteorology, 20, 1527-1532.

Chen, J. M. (1996). Canopy architecture and remote sensing of the fraction of photosynthetically active radiation absorbed by boreal conifer forests. IEEE Transactions on Geoscience and Remote Sensing, 34, 1353-1368.

Chen, J. M., Govind, A., Sonnentag, O., Zhang, Y. Q., Barr, A., \& Amiro, B. D. (2006). Leaf area index measurements at Fluxnet-Canada forest sites. Agricultural and Forest Meteorology, 140, 257-268.

Coleman, T. F., \& Li, Y. Y. (1996). An interior trust region approach for nonlinear minimization subject to bounds. SIAM Journal on Optimization, 6, 418-445.

Coleman, T. F., Liu, J. G., \& Yuan, W. (2002). A new trust-region algorithm for equality constrained optimization. Computational Optimization and Applications, 21, 177-199.

Coops, N. C., Hilker, T., Hall, F. G., Nichol, C. J., \& Drolet, G. G. (2010). Estimation of lightuse efficiency of terrestrial ecosystem from space: A status report. Bioscience, 60 788-797.

Demmig-Adams, B., \& Adams, W. W. (1996). The role of xanthophyll cycle carotenoids in the protection of photosynthesis. Trends in Plant Science, 1, 21-26.

Field, C., \& Mooney, H. A. (1986). The photosynthesis-nitrogen relationship in wild plants. In T. J. Givnish (Ed.), On the economy of plant form and function; sixth Maria Moors Cabot Symposium on Evolutionary constraints on primary productivity: Adaptive patterns of energy capture in plants, Harvard Forest, Mass., USA, Aug. 6 , 1983 (pp. 25-56). New York, N.Y., USA: Cambridge, England. Illus: Cambridge University Press Xvii $+717 \mathrm{pp}$.

Gomez-Chova, L., Alonso, L., Guanter, L., Camps-Valls, G., Calpe, J., \& Moreno, J. (2008) Correction of systematic spatial noise in push-broom hyperspectral sensors: Application to CHRIS/PROBA images. Applied Optics, 47, F46-F60.

Goulden, M. L., Munger, J. W., Fan, S. M., Daube, B. C., \& Wofsy, S. C. (1996). Exchange of carbon dioxide by a deciduous forest: Response to interannual climate variability. Science, 271, 1576-1578.

Hall, F. G., Hilker, T., \& Coops, N. C. (2011). PHOTOSYNSAT, photosynthesis from space: Theoretical foundations of a satellite concept and validation from tower and spaceborne data. Remote Sensing of Environment, 115, 1918-1925.

Hall, F. G., Hilker, T., Coops, N. C., Lyapustin, A., Huemmrich, K. F., Middleton, E., et al (2008). Multi-angle remote sensing of forest light use efficiency by observing PRI variation with canopy shadow fraction. Remote Sensing of Environment, 112, 3201-3211.

Hall, F. G., Hilker, T., \& Coops, N. C. (this issue). Data assimilation of photosynthetic light-use efficiency using multi-angular satellite data: I. Model formulation. Remote Sensing of Environment.

Heinsch, F. A., Zhao, M. S., Running, S. W., Kimball, J. S., Nemani, R. R., Davis, K. J., et al. (2006). Evaluation of remote sensing based terrestrial productivity from modis using regional tower eddy flux network observations. IEEE Transactions on Geoscience and Remote Sensing, 44, 1908-1925.

Hilker, T., Coops, N. C., Coggins, S. B., Wulder, M. A., Brown, M., Black, T. A., et al. (2009). Detection of foliage conditions and disturbance from multi-angular high spectral resolution remote sensing. Remote Sensing of Environment, 113, 421-434.

Hilker, T., Coops, N. C., Hall, F. G., Black, T. A., Chen, B., Krishnan, P., et al. (2008). A modeling approach for upscaling gross ecosystem production to the landscape scale using remote sensing data. Journal of Geophysical Research-Biogeosciences, 113.

Hilker, T., Coops, N. C., Hall, F. G., Nichol, C. J., Lyapustin, A., Black, T. A., et al. (2011). Inferring terrestrial photosynthetic light use efficiency of temperate ecosystems from space. Journal of Geophysical Research-Biogeosciences, 116, G03014.

Hilker, T., Coops, N. C., Schwalm, C. R., Jassal, R. S., Black, T. A., \& Krishnan, P. (2008). Effects of mutual shading of tree crowns on prediction of photosynthetic lightuse efficiency in a coastal Douglas-fir forest. Tree Physiology, 28, 825-834.
Hilker, T., Hall, F. G., Coops, N. C., Lyapustin, A., Wang, Y., Nesic, Z., et al. (2010). Remote sensing of photosynthetic light-use efficiency across two forested biomes: Spatial scaling. Remote Sensing of Environment, 114, 2863-2874.

Hilker, T., Lyapustin, A., Hall, F. G., Wang, Y., Coops, N. C., Drolet, G., et al. (2009). An assessment of photosynthetic light use efficiency from space: Modeling the atmospheric and directional impacts on PRI reflectance. Remote Sensing of Environment, 113, 2463-2475.

Hilker, T., van Leuuwen, M., Coops, N. C., Wulder, M. A., Newnham, G. J., Jupp, D. L., et al (2010). Comparing canopy metrics derived from terrestrial and airborne laser scanning in a Douglas-fir dominated forest stand. Trees, 24, 819-832.

Hollinger, D. Y., Aber, J., Dail, B., Davidson, E. A., Goltz, S. M., Hughes, H., et al. (2004). Spatial and temporal variability in forest-atmosphere $\mathrm{CO}(2)$ exchange. Global Change Biology, 10, 1689-1706.

Horii, C. V., Munger, J. W., Wofsy, S. C., Zahniser, M., Nelson, D., \& McManus, J. B. (2004). Fluxes of nitrogen oxides over a temperate deciduous forest. Journal of Geophysical Research-Atmospheres, 109.

Humphreys, E. R., Black, T. A., Morgenstern, K., Cai, T. B., Drewitt, G. B., Nesic, Z., et al. (2006). Carbon dioxide fluxes in coastal Douglas-Fir stands at different stages of development after clearcut harvesting. Agricultural and Forest Meteorology, 140, 6-22.

Jarvis, P. G. (1976). Interpretation of variations in leaf water potential and stomatal conductance found in canopies in field. Philosophical Transactions of the Royal Society of London. Series B, Biological Sciences, 273, 593-610.

Kidston, J., Brummer, C., Black, T. A., Morgenstern, K., Nesic, Z., McCaughey, J. H., et al. (2010). Energy balance closure using eddy covariance above two different land surfaces and implications for $\mathrm{CO}(2)$ flux measurements. Boundary-Layer Meteorology, $136,193-218$.

Li, X. W., \& Strahler, A. H. (1985). Geometric-optical modeling of a conifer forest canopy. IEEE Transactions on Geoscience and Remote Sensing, 23, 705-721.

Lowe, D. G. (2004). Distinctive image features from scale-invariant keypoints. International Journal of Computer Vision, 60, 91-110.

Lyapustin, A., Wang, Y., Kahn, R., Xiong, J., Ignatov, A., Wolfe, R., et al. (2007). Analysis of MODIS-MISR calibration differences using surface albedo around AERONET sites and cloud reflectance. Remote Sensing of Environment, 107, 12-21.

Ma, J. L., Chan, J. C. W., \& Canters, F. (2010). Fully automatic subpixel image registration of multiangle CHRIS/Proba data. IEEE Transactions on Geoscience and Remote Sensing, $48,2829-2839$.

Monteith, J. L. (1972). Solar-radiation and productivity in tropical ecosystems. Journal of Applied Ecology, 9, 747-766.

Monteith, J. L. (1977). Climate and efficiency of crop production in Britain. Philosophical Transactions of the Royal Society of London. Series B, Biological Sciences, 281, 277-294.

Morgenstern, K., Black, T. A., Humphreys, E. R., Griffis, T. J., Drewitt, G. B., Cai, T. B., et al (2004). Sensitivity and uncertainty of the carbon balance of a Pacific Northwest Douglas-Fir forest during an El Niño La Niña cycle. Agricultural and Forest Meteorology, 123, 201-219.

Munger, J. W., Wofsy, S. C., Bakwin, P. S., Fan, S. M., Goulden, M. L., Daube, B. C., et al. (1996). Atmospheric deposition of reactive nitrogen oxides and ozone in a temperate deciduous forest and a subarctic woodland .1. Measurements and mechanisms. Journal of Geophysical Research-Atmospheres, 101, 12639-12657.

Running, S. W., Nemani, R. R., Heinsch, F. A., Zhao, M. S., Reeves, M., \& Hashimoto, H. (2004). A continuous satellite-derived measure of global terrestrial primary production. Bioscience, 54, 547-560.

Schwalm, C. R., Black, T. A., Arniro, B. D., Arain, M. A., Barr, A. G., Bourque, C. P. A., et al. (2006). Photosynthetic light use efficiency of three biomes across an East-west continental-scale transect in Canada. Agricultural and Forest Meteorology, 140, 269-286.

Staebler, R. M., \& Fitzjarrald, D. R. (2005). Measuring canopy structure and the kinematics of subcanopy flows in two forests. Journal of Applied Meteorology, 44 1161-1179.

Thuillier, G., Herse, M., Labs, D., Foujols, T., Peetermans, W., Gillotay, D., et al. (2003). The solar spectral irradiance from 200 to $2400 \mathrm{~nm}$ as measured by the SOLSPEC spectrometer from the ATLAS and EURECA missions. Solar Physics, 214, 1-22.

Turner, D. P., Ritts, W. D., Cohen, W. B., Gower, S. T., Zhao, M. S., Running, S. W., et al. (2003). Scaling Gross Primary Production (GPP) over boreal and deciduous forest landscapes in support of MODIS GPP product validation. Remote Sensing of Environment, 88, 256-270.

Verstraete, M. M., Pinty, B., \& Myneni, R. B. (1996). Potential and limitations of information extraction on the terrestrial biosphere from satellite remote sensing. Remote Sensing of Environment, 58, 201-214.

Xiao, X. M., Zhang, Q. Y., Hollinger, D., Aber, J., \& Moore, B. (2005). Modeling gross primary production of an evergreen needleleaf forest using modis and climate data. Ecological Applications, 15, 954-969.

Zha, T., Barr, A. G., Black, T. A., McCaughey, J. H., Bhatti, J., Hawthorne, I., et al. (2009). Carbon sequestration in boreal jack pine stands following harvesting. Global Change Biology, 15, 1475-1487.

Zhao, M. S., Heinsch, F. A., Nemani, R. R., \& Running, S. W. (2005). Improvements of the MODIS terrestrial gross and net primary production global data set. Remote Sensing of Environment, 95, 164-176. 